\title{
Intrinsic activation of cardiosphere-derived cells enhances myocardial repair
}

\author{
Toshikazu Sano, MD, PhD, ${ }^{\mathrm{a}}$ Tatsuo Ito, $\mathrm{MD}, \mathrm{PhD},{ }^{\mathrm{b}}$ Shuta Ishigami, MD, PhD, ${ }^{\mathrm{a}}$ \\ Srinivas Bandaru, MSc, PhD, ${ }^{b}$ and Shunji Sano, MD, $\mathrm{PhD}^{\mathrm{a}}$
}

\section{ABSTRACT}

Objective: Permanent loss of cardiomyocytes after myocardial infarction results in irreversible damage to cardiac function. The present study aims to enhance the cardiomyogenic efficiency of cardiosphere-derived cells (CDCs) to develop into large populations of cardiomyocytes by intrinsic activation of cardio-specific differentiation factors (Gata4, Mef2c, Nkx2-5, Hand2, and Tnnt2) by a CRISPR/dCas9 assisted transcriptional enhancement system.

Methods: Exhaustive screening was performed to identify the specific sequences in endogenous regulatory regions (enhancers and promoters) responsible for transcriptional activation of the target genes, via a CRISPR/dCas9 system fused with transcriptional activator VP64 (CRISPR-dCas9-VP64). In a rat model of acute myocardial infarction, we compared the regenerative potential and functional benefits of CDCs with or without transcriptional activation.

Results: We identified a panel of specific CRISPR RNA targeting the enhancers and promoters, which demonstrated significantly higher expression of differentiation factors of Gata4, Hand2, and Tnnt2. The group of CDCs with transcriptional activator VP64 (CDC with VP64) showed significant improvement in the left ventricular ejection fraction (61.9\% vs $52.5 \%$ and $44.1 \%$ in the CDC without transcriptional activation group and control) and decreased scar area in the heart.

Conclusions: We have identified endogenous regulatory regions responsible for an intrinsic activation of cardio-specific differentiation factors assisted via a CRISPR/ dCas9 gene transcriptional system. The CRISPR/dCas9 system may provide an efficient and effective means of regulating Tnnt2 gene activation within stem cells. Subsequently, this system can be used to enhance transplanted CDCs differentiation potential within ischemic myocardia to better therapeutic outcomes of patients with ischemic heart disease. (J Thorac Cardiovasc Surg 2022;163:1479-90)

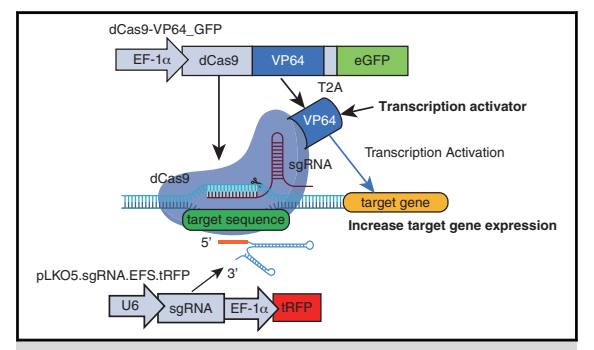

Enhance the cardiosphere-derived cells to develop into a population of cardiomyocytes.

CENTRAL MESSAGE

The study is centered on intrinsic transcriptional activation of differentiation factors in the cellular environment by a CRISPR/dCas9 gene transcriptional system to produce active cardiomyocytes.

\section{PERSPECTIVE}

External induction of differentiation factors may be supplemented to cardiosphere-derived cells for effective differentiation of myocytes, although this may lead to uncontrolled proliferation. The present study focused on intrinsic transcriptional activation of differentiation factors in the cellular environment and could be combined with the external induction of differentiation factors.

See Commentaries on pages 1491 and 1494 .
From the a Division of Pediatric Cardiothoracic Surgery, Department of Surgery, University of California at San Francisco, San Francisco, Calif; and ${ }^{\mathrm{b}}$ Department of Hygiene, Kawasaki Medical University, Okayama, Japan.

Received for publication Dec 19, 2019; revisions received May 1, 2020; accepted for publication May 1, 2020; available ahead of print May 29, 2020.

Address for reprints: Shunji Sano, MD, PhD, Division of Pediatric Cardiothoracic Surgery, Department of Surgery, University of California San Francisco, 550 16th St, Floor 5, San Francisco, CA 94158 (E-mail: Shunji.Sano@ucsf.edu). 0022-5223/\$0.00

Published by Elsevier Inc. on behalf of The American Association for Thoracic Surgery. This is an open access article under the CC BY-NC-ND license (http:// creativecommons.org/licenses/by-nc-nd/4.0/).

https://doi.org/10.1016/j.jtcvs.2020.05.040
Acute myocardial infarction is a common cardiac emergency with the potential for substantial morbidity and mortality. Irreversible damage to cardiomyocytes after myocardial infarction results in fibrosis and decreases the cardiac function, subsequently leading to ischemic heart failure. ${ }^{1}$ Despite improvements in postmyocardial infarction therapy, along with cardiac assist devices, current

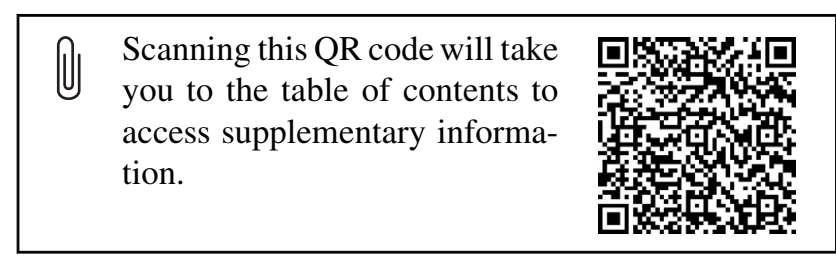




\section{Abbreviations and Acronyms \\ CDCs = cardiosphere-derived cells \\ CRISPR $=$ clustered regularly interspaced short palindromic repeat \\ crRNA $=$ CRISPR RNA \\ dCas9 = dead Cas9 \\ IGF-1 = insulin-like growth factor 1 \\ PBS $=$ phosphate buffered saline \\ sgRNA $=$ single guide RNA \\ VEGF $=$ vascular endothelial growth factor}

treatment is palliative and cannot restore the cardiac function or maintain normal heart function long term. ${ }^{1,2}$

In recent years, there has been greater interest in myocardial regeneration with the application of stem cells. ${ }^{3,4}$ Some clinical trials have used various types of autologous transplanted cells, such as adipose tissue-derived mesenchymal stem cells, ${ }^{5}$ bone marrow-derived mesenchymal stem cells, ${ }^{6,7}$ and cardiosphere-derived cells (CDCs). ${ }^{8}$ These trials have shown an increase in viable myocardial tissue as well as a decrease in the infarct size. Although several forms of cell therapies have been beneficial in improving cardiac function after infarction, the cells used are not natural residents of cardiac tissue, and it is controversial as to whether they can truly regenerate lost myocardium. In principle, CDC populations may offer major advantages over extracardiac cell sources because cardiac progenitors differentiate along either the cardiomyocytic or vascular lineages, which both survive well in the myocardial environment. CDCs constitute a candidate pool of such cardiac stem cells that comprise a heterogeneous population of cardiac cells, including a potentially clonogenic stem cell subpopulation. Recent studies have revealed that cell transplantation stimulates endogenous cardiac repair process via paracrine signaling, direct cell-to-cell interaction, and/or transfer of microRNAs from exosomes that influence the transcriptional activity of host cells. ${ }^{9}$

Synthetic transcriptional activators derived from the clustered regularly interspaced short palindromic repeat (CRISPR)-Cas9 system are emerging as powerful new tools for activating the endogenous expression of genes. Socalled dead Cas9 (dCas9) is a variant of the Cas9 nuclease whose endonucleolytic activity has been removed. This dCas9 fused with certain transcriptional activators, such as dCas9-VP64 or dCas9-VPR, can activate multiple specific gene expressions by the guide of single guide (sgRNAs) in any kind of cells. This fact opens new possibilities for myocardial transplantation treatment, and at the same time, increases the risk that dCas9's flexible gene activation may cause an unexpected invasion of recipient tissues. The gene targeted by dCas9 should be sufficient but minimally invasive, with emphasis on recipient benefits.
The adult human heart contains small populations of endogenous committed cardiac stem cells or multipotent CDCs. These stem cells are intrinsically programmed to generate cardiomyocytes. ${ }^{10}$ A large number of experiments in vitro and also in animal models proved the cardiomyogenic potential of CDC derivatives. ${ }^{11,12}$ However, the intracoronary infusions of CDCs differentiating into cardiomyocytes exhibited limited self-renewal and differentiation potential to become functional cardiomyocytes. ${ }^{8,13} \mathrm{CDCs}$ undoubtedly form the most favorable candidate stem cell for cardiac regenerative therapy; however, the reduced differentiation potential of CDCs to develop into a functional population of cardiomyocytes has always been a significant setback. The present study, therefore, centers on enhancing the cardiomyogenic efficiency of CDCs to develop into a large population of cardiomyocytes by intrinsic activation of cardio-specific differentiation factors (Gata4, Mef2c, Nkx2- 5, Hand2, and Tnnt2) via the CRISPR/dCas9 gene transcriptional enhancement system.

\section{MATERIALS AND METHODS \\ Animal Studies}

The experimental animal protocols were approved by the University of California, San Francisco Institutional Animal Care and Use Committee (AN179985-01). All surgeries were performed under general anesthesia, and all efforts were made to minimize animal suffering. Animal surgery was performed as previously reported with slight modifications. ${ }^{14}$ In brief, 7- to 8-week-old Sprague Dawley female rats were intubated and connected to a rodent ventilator under an anesthetized condition with approximately $2 \%$ to $5 \%$ sevoflurane. A left thoracotomy was performed along with the fourth or fifth intercostal space, exposing the beating heart. Myocardial infarction was induced by permanent ligation of the left anterior descending coronary artery. A 6-0 Prolene suture was placed around the left anterior descending coronary artery and knotted tightly, resulting in immediate ischemia of the downstream myocardial tissue. Infarction was confirmed by changes in tissue discoloring and reduced wall motion. To prevent arrhythmias and subsequent sudden death, the left anterior descending coronary artery was ligated distally. Echocardiography was performed to confirm the ligation model using a Visual Sonics Vevo 3100 (FujiFilm, Tokyo, Japan) equipped with a 10-MHz transducer. Two days after myocardial infarction induction, the rats were separated into 3 groups: VP64-transinduced CDCs (CDC with VP64) group, nontransinduced CDCs (CDC) group, and phosphate buffered saline (PBS) only (control) group. The CDCs with or without transcriptionally activated differentiation factors mediated by CRISPR-dCas9-VP64 were directly injected into the infarcted rat myocardium following the thoracotomy procedures. An amount equal to $1 \times 10^{6}$ rat CDCs, suspended in $100 \mu \mathrm{L}$ PBS were injected at 4 sites of the infarct border zone of the left ventricle. An equal volume of PBS was injected as in the control group.

\section{Rat CDC Culture and Transplantation}

The hearts were excised from neonatal rats under the general anesthetic condition and the tissue was processed immediately. The obtained myocardial specimens were minced and digested with $0.2 \%$ type II collagenase to obtain single cell suspensions to generate cardiospheres as described previously. ${ }^{11}$ Cardiospheres were mechanically selected from the cultures and expanded in Dulbecco's Modified Eagle Medium/F12 medium containing $10 \%$ fetal bovine serum, $2 \%$ penicillin, and streptomycin. 


\section{Screening for Promoter/Enhancer Regions in Differentiation Factors Gene for CRISPR-dCas9- Mediated Transcriptional Activation in CDCs}

An exhaustive screening was performed to identify the specific sequences in endogenous regulatory regions (enhancers and promoters) responsible for transcriptional activation of the gene. Computational based functional motif finding programs (SW, TSSG, Fprom, TSSP, TSSP-TCM, and PromH) assisted by hidden Markov models and linear discriminant functions were implemented to identify the promoters and enhancers both upstream and downstream of the transcription start site of target genes.

\section{Guide Design, Cloning Constructs, and Transfections}

To explore the CRISPR/dCas9 system for activation of multiple cardiospecific genes, we chose the dCas9-VP64 system and constructed a cassette expressing a dCas9-VP64 fusion protein. The CRISPR RNA (crRNAs) specifically targeting the enhancer and promoter sites spanning more than 28 consecutive bases were designed in SnapGene software version 4.2.4 (GSL Biotech, San Diego, Calif). The crRNAs were further validated for their nonspecific base pairing in the total rat transcriptome by GG genome browser (https://gggenome.dbcls.jp), which assured the designed crRNAs would be target-specific (Tables E1-E5). Additionally, guides with selfcomplementarities and the propensity to form dimers were not considered before the cloning process. To generate lentivirus vectors, dCas-VP64GFP, and pLKO5.sgRNA.EFS.tRFP (addgene), including sgRNA sequences, were individually co-transfected with pCMV-VSV-G, which served as an envelope protein for producing lentiviral particles, into HEK293FT packaging cell (Figure 1, $A$ and $B$ ). Generated lentiviral sgRNA or dCas9VP64-GFP vectors were transfected into the CDCs. In acute myocardial infarction rat models, we compared the regenerative potential and functional benefits of CDCs with or without transcriptional activation (Figure 1,C).

\section{Echocardiography}

Left ventricular function was assessed using echocardiography. Baseline echocardiograms were acquired at day- 1 after myocardial infarction to determine the extent and the location of the infarcted area. Rats with baseline ejection fraction above $50 \%$ were excluded from the study. Two-dimensional M-mode and Doppler imaging were performed. Images were obtained from the parasternal long axis view at the mid-papillary level to assess the diameter of the left ventricle (systolic and diastolic), left ventricular ejection fraction, and percent fractional shortening. Cardiac function was monitored until 4 weeks after myocardial infarction induction to assess the quality of CDC engraftment.

\section{Invasive Hemodynamics}

Left ventricular pressure, ejection fraction, end-diastolic volume, endsystolic volume, cardiac output, and stroke volume were measured by a pressure-volume catheter (1.9Fr) under anesthesia with approximately $2 \%$ to $5 \%$ sevoflurane in open-chest conditions (Transonic Systems, Ithaca, NY).

\section{Histological Analysis}

Isolated hearts were fixed in $10 \%$ formalin overnight at room temperature and embedded in paraffin, and tissue sections (4 $\mu \mathrm{m}$ thickness) were used for histological analysis. Masson's trichrome staining was performed to assess fibrosis in the infarcted area. The Masson's trichrome stained area and peri-infarct area were evaluated in stacked images using a BZ-X700 Analyzer (Osaka, Japan).

\section{Quantification of Growth Factor Secretion and Gene Expression}

Enzyme-linked immunosorbent assays were used to determine the secretion level of the vascular endothelial growth factor (VEGF) and insulin-like growth factor 1 (IGF-1) in the culture media of CDCs in fetal bovine serum-free Iscove's Modified Dulbecco's Medium (Gibco, Gaithersburg, Md) for 3 days using the rat VEGF and IGF-1 Quantikine immunoassay kit (R\&D Systems, Minneapolis, Minn) according to the manufacturer's instructions. The messenger RNA expression levels of differentiation factors (Gata4, Mef2c, Nkx2-5, Hand2, Tnnt2, Sirpa, Acta2 and Col1a1) from the transfected CDCs were analyzed using the quantitative polymerase chain reaction. Total RNA from the transfected CDCs was purified using the Isolate II RNA Mini Kit (Bioline, Taunton, Mass). The transcripts of differentiation factors expressed in CDCs were quantified by real-time quantification polymerase chain reaction by reverse transcription with a QuantiTect reverse transcription kit (Qiagen, Venlo, the Netherlands). Total RNA from the apex of the heart was also extracted with Trizol reagent (Invitrogen, Waltham, Mass) followed by reverse transcription with a QuantiTect reverse transcription kit to check the inflammatory factors (matrix metalloproteinase type 2/9, tissue inhibitor of metalloproteinase $1 / 2$, interleukin-6, collagen type 1 , collagen type 3 ) and cardiac growth factors (VEGFa and IGF-1). Primer sequences are listed in Table E6. Real-time quantitative polymerase chain reaction was performed by StepOnePlus with TaqMan fast advanced master mix (Applied Biosystems, Foster City, Calif). Glyceraldehyde-3-phosphate dehydrogenase was used as a reference point for the obtained data.

\section{Statistical Analysis}

Quantitative variables are presented as mean \pm standard deviation unless indicated otherwise. Statistical changes from baseline within group were tested using paired $t$ test. One-way analysis of variance was used for multiple group comparisons. If significant differences were found, the Tukey-Kramer post-hoc test was conducted using the SPSS software version 26 (IBM-SPSS Corp, Armonk NY). All reported $P$ values are 2-tailed.

\section{RESULTS}

\section{Design and Construction of CRISPR/dCas9 System}

The CRISPR/dCas9 system fused with a transcriptional activator (CRISPR-dCas9-VP64) and assisted by crRNA was recruited at the target sequence stretch enabling enhanced expression of the gene. We selected Gata4, Mef2c, Nkx2-5, Hand2, and Tnnt2 as the cardio-specific target genes to identify whether dCas9-based transcriptional activators could regulate endogenous gene expression in CDCs using single and multiple sgRNAs. To identify the most efficient binding for gene induction, multiple sgRNAs were designed targeting the potential promoter and enhancer regions in the upstream and downstream at the transcription start site of each of the target genes, which can enhance the expression of differentiation factors (Figure 2, A-E).

\section{Expression Analysis of Differentiation Factors in CDCs}

Expression of differentiation factors corresponding to the stimulation of dCas9-VP64 with each sgRNA guide was analyzed by the quantitative polymerase chain reaction. dCas9-VP64 alone was used as a control. We tested whether sgRNA-guided activators could induce expression of the cardio-specific factors, especially the Tnnt 2 gene. At first, we used 9 or 11 sgRNAs targeted to sequences in a 

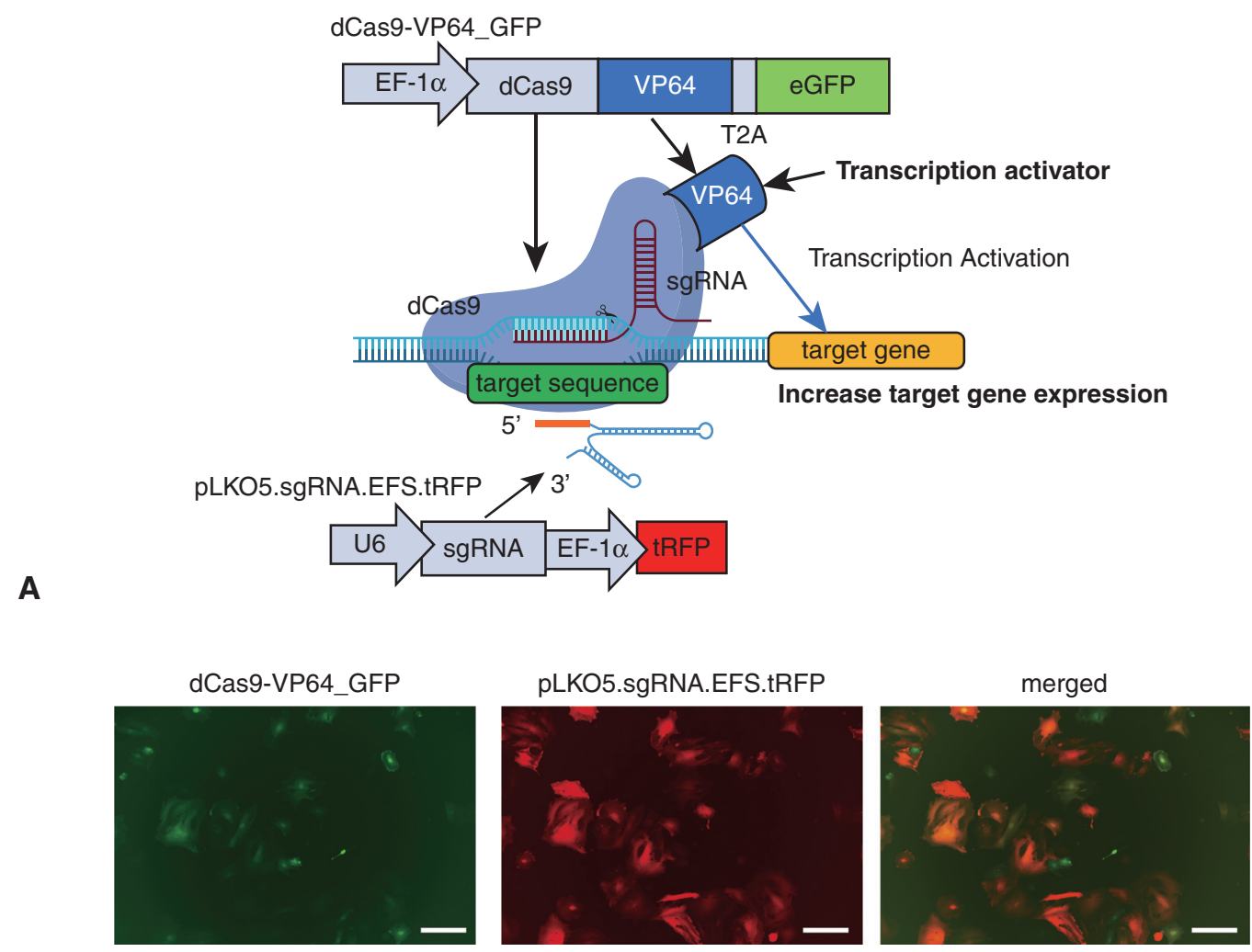

B

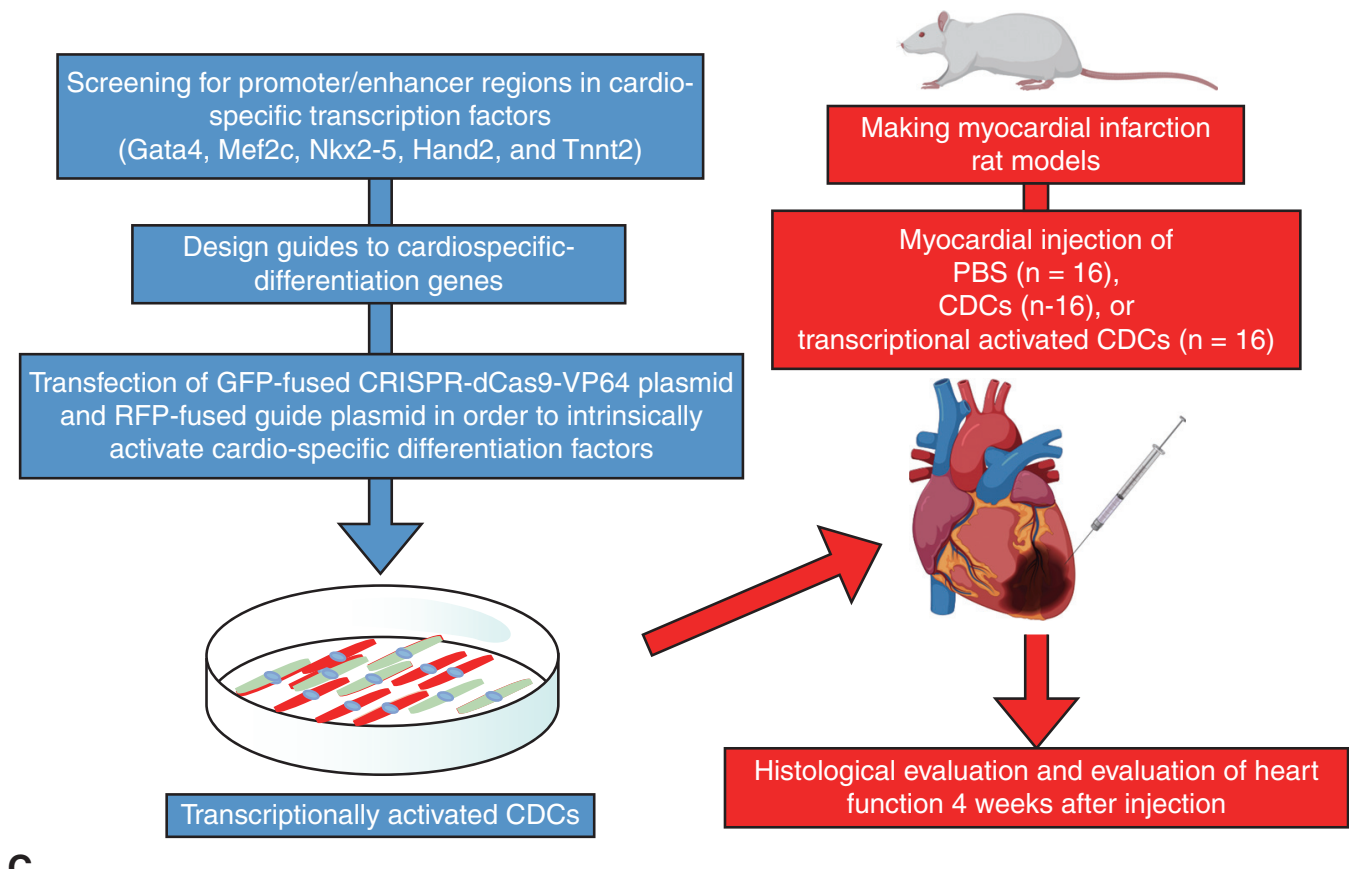

FIGURE 1. CRISPR-dCas9 transcriptional activation system and overview of this study. A, Targeted transcriptional activation of endogenous genes can be achieved by using the dCas9/single guide RNA ( $g R N A$ ) DNA-binding platform to recruit strong transcriptional activators (VP64). Guide RNA, which is a small piece of predesigned RNA, binds to the target sequence. Unlike Cas9, dCas9 does not have the ability to cut double-strand DNA. However, it can still target and bind DNA when guided by sgRNA. B, Cardiosphere-derived cells $(C D C s)$ were transfected with a dCas9 fused to green fluorescent protein $(G F P)$ (dCas9-GFP) and a sgRNA fused to red fluorescent protein $(R F P)(s g R N A-R F P)$. These 2 transfections allowed the CDCs to fluoresce green and red, respectively. Emitting both green and red fluorescence (ie, merged) indicated successful transfections of dCas 9 and guide, which are essential factors for the CRISPR-dCas9 system. White scale bar: $100 \mu \mathrm{m}$. C, Schematic representation of the overview of this study. PBS, Phosphate buffered saline. 


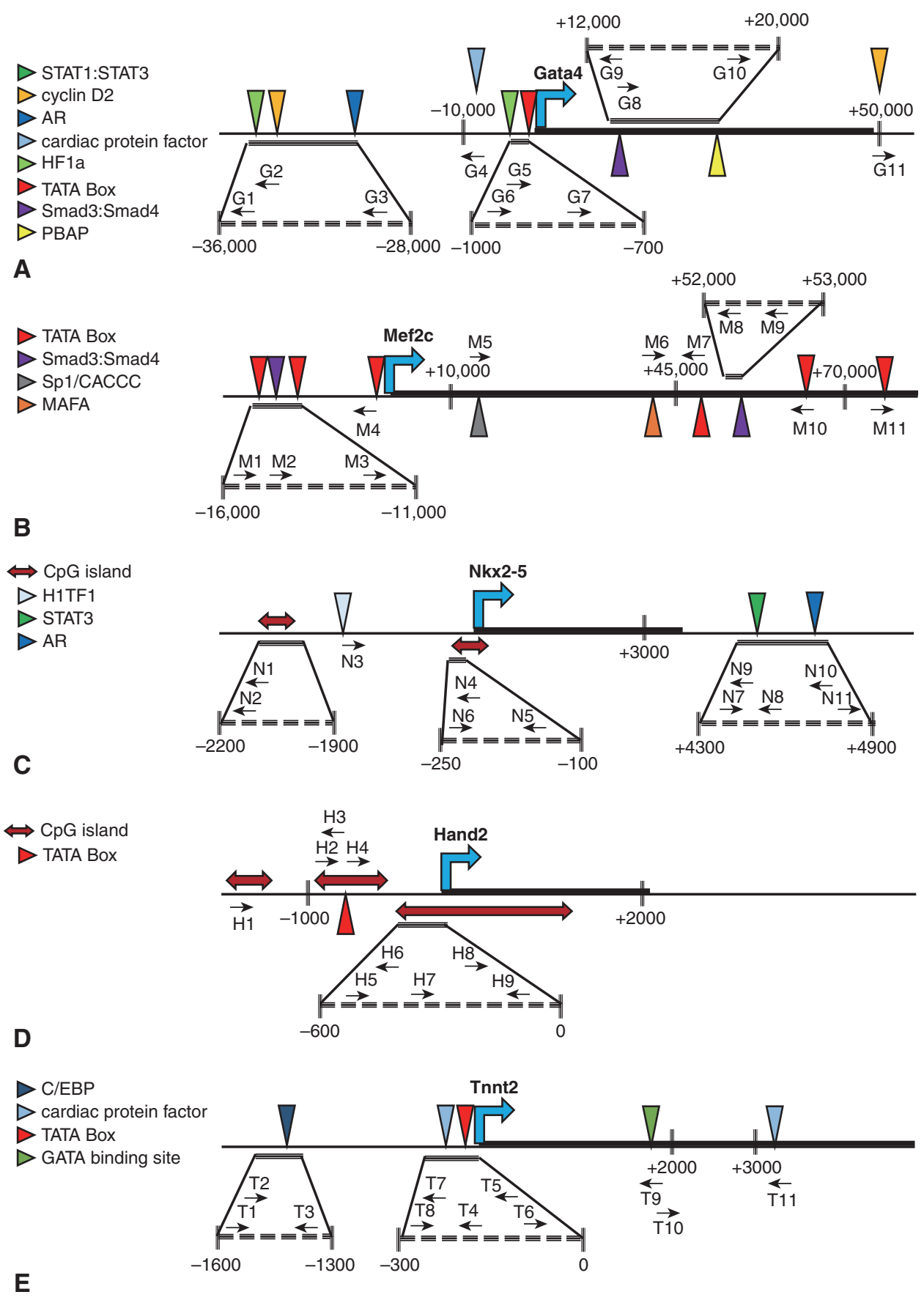

FIGURE 2. Designs of promoter/enhancer regions in cardio-specific differentiation factors. Target sequences of single guide RNA ( $s g R N A s)$ to the Gata4 (A), Mef2c (B), Nkx2-5 (C), Hand2 (D), and Tnnt2 (E) genes are shown. A, The locations of the first 20 nucleotides of 11 sgRNAs (black arrows, pointing in the $5^{\prime}$ to $3^{\prime}$ direction) were targeted to the endogenous rat Gata4 gene promoter. B, Locations of 11 sgRNAs were targeted to the endogenous rat Mef2c gene promoter (M1-M11), represented in (A). C, Locations of 11 sgRNAs targeted to the endogenous rat Nkx2-5 gene promoter (N1-N11), represented as in (A). D, Locations of 9 sgRNAs targeted to the endogenous rat Hand2 gene promoter (H1-H9), represented in (A). E, Locations of 11 sgRNAs targeted to the endogenous rat Tnnt2 gene promoter (T1-T11), represented in (A). Blue arrows represent the transcription start site in each gene (A-E). Potential promoter and enhancer regions in the upstream and downstream sites of each gene were represented by inverted color triangles (A-E). $A R$, Androgen receptor; $C / E B P$, CCAAT/enhancer binding protein; $H F 1 \alpha$, hypozia-inducible factor 1, alpha subunit; $M A F A$, musculoaponeurotic fibrosarcoma oncogene homolog A; $P B A P$, polybromo-containing Brahma associated proteins complex; Smad, small mothers against decapentaplegic; Sp1, specificity protein 1; STAT, single transducer and activator of transcription protein. 
predicted promoter and enhancer regions of the rat genes Gata4 (G1-11), Mef2c (M1-11), Nkx2-5 (N1-11), Hand2 (H1-9), and Tnnt2 (T1-11). Expression of G1 and G2 sgRNAs induced significant increases in the Gata4 transcript gene but did not induce elevated Tnnt2 expression. However, expression of G8 sgRNAs induced significant increase in Tnnt2 expression while this sgRNA did not enhance Gata4 transcript activation (Figure 3, A). All 11 sgRNAs that target expected promoter/enhancer region of $M e f 2 c$ gene did not have the potential to elevate Mef $2 c$ or Tnnt 2 expression (Figure 3,B). As in the case of G1 and G2 sgRNAs, expression of N6, N8, H1, H2 and H8 sgRNAs induced significant increases in each target gene's expression; however, these sgRNAs did not induce elevated Tnnt2 expression (Figure 3, $C$ and $D$ ). Of 11 sgRNAs in the promoter/enhancer region of Tnnt2 gene, 4 sgRNAs (T1, T2, T9, and T10) induced significant increases in Tnnt2 gene expression (Figure 3,E).

We envisioned that expression of multiple guide RNAs in a single cell might enable synergistic activation of endogenous gene targets as recently described. ${ }^{15}$ By combining sets of 2 to 4 sgRNAs from the each group of the target sgRNAs that were designed, we observed successful synergistic activation of each gene expression within all Gata4, Nkx2-5, and Tnnt2 sgRNA combinations. However, synergistic activation in 3 cardiospecific genes was identified only in combinations of $\mathrm{T} 1+\mathrm{T} 2+\mathrm{T} 6+\mathrm{T} 9$ (Table E7). As expected, most gene combinations exhibited no change of gene expression with other cell types of genes (Sirpa, Acta2, and Collal) (Figure 4, A). Increasing evidence supports the generalization that cell therapy boosts cardiac function largely via paracrine mechanisms. ${ }^{16}$ We thus compared the production of growth factors by the various transcriptional activation sites. Multiple guide RNAs in Tnnt2 genes were unique in their ability to secrete large amounts of IGF-1 (Figure 4, $B$ ).

\section{Improvement in Cardiac Function Transplanted With Transcription-Activated CDCs}

Echocardiographic measurement was performed at 1 day and 4 weeks after myocardial infarction to investigate the change in left ventricular function. In in vivo studies, we used guide combinations of $\mathrm{T} 1+\mathrm{T} 2+\mathrm{T} 6+\mathrm{T} 9$ as the CDC with VP64 group. Compared with the control group, left ventricular ejection fraction, and percent fractional shortening at 4 weeks after myocardial infarction increased in both the CDC and CDC with VP64 groups (left ventricular ejection fraction: $45.0 \% \pm 4.9 \%$ vs $50.0 \% \pm 4.5 \%$ $[P=.01]$ and $52.2 \% \pm 6.5 \%[P=.001]$ in the $\mathrm{CDC}$ and CDC with VP64 groups and percent fractional shortening: $23.2 \% \pm 2.8 \%$ vs $26.3 \% \pm 2.8 \%[P=.006]$ and $27.8 \% \pm 4.1 \%[P<.001]$ in the CDC and CDC with VP64 groups), whereas no significant difference was observed between the CDC and CDC with VP64 groups (Figure 5, $A$ and $B$ ). There was no significant difference in left ventricular end-diastolic dimension and left ventricular end-systolic dimension between 3 groups in echocardiography (Figure 5, $C$ and $D$ ). The quantitative data of echocardiographic measurement was shown on Table E8. However, in evaluating hemodynamics via cardiac catheter, CDC with VP64 group showed an apparently increased stroke work $(12.0 \pm 3.8$ vs $7.8 \pm 1.6 \mathrm{~mm} \mathrm{Hg} \times \mathrm{mL}$ $[P<.001]$ in the control group), which refers to the work done by the ventricle to eject a volume of blood, and improved ventricular function $(61.9 \% \pm 10.6 \%$ vs $44.1 \% \pm 6.4 \%[P<.001]$ and $52.5 \% \pm 7.7 \%[P=.01]$ in the control and CDC groups) (Figure 5, $E$ and $F$ ). In accordance with the results above, the therapeutic effect was most pronounced for the CDC with VP64 group, which showed a marked reduction in left ventricular end-diastolic and systolic volumes compared with both the control and CDC groups (left ventricular end-diastolic volume: $260.1 \pm 40.5 \mu \mathrm{L}$ vs $337.8 \pm 74.8 \mu \mathrm{L}[P=.003]$ and $324.2 \pm 62.5 \mu \mathrm{L}[P=.004]$ in the control and CDC groups; left ventricular end-systolic volume: $115.6 \pm 34.6 \mu \mathrm{L}$ vs $172.0 \pm 35.5 \mu \mathrm{L}[P<.001]$ and $162.6 \mu \mathrm{L} \pm 38.3 \mu \mathrm{L}$ $[P=.003]$ in the control and CDC groups) (Figure 5, $G$ and $H$ ). The quantitative data of cardiac catheter measurement was shown on Table E9.

\section{Chemokine Levels and Ventricular Remodeling in Rats After CDC Infusion}

To verify the underlying mechanisms involved in myocardium repair after CDC treatment, chemokine levels in the infarcted heart 4 weeks after myocardial infarction were analyzed by quantitative polymerase chain reaction. Relevant biomarkers linked with cardiac remodeling (matrix metalloproteinase type 2, interleukin 6 , collagen type 1 , and collagen type 3 ) were suppressed significantly in the CDC with VP64 group compared with the control group. In particular, the level of interleukin 6 was markedly suppressed compared with the CDC group. The chemokine level of tissue inhibitor of metalloproteinase 1 was relatively higher in the CDC with VP64 group compared with the levels in the control and CDC group. No marked difference was observed in matrix metalloproteinase type 9 and tissue inhibitor of metalloproteinase 2 among the 3 groups. Furthermore, compared with the control group, the CDC with VP64 group significantly increased cardiac growth factors such as VEGF and IGF-1 (Figure 6, A). To clarify the morphological consequences, heart specimens were histologically analyzed by Masson's trichrome for scar area evaluation. Compared with the control group, the injections from the CDC and CDC with VP64 groups significantly decreased scar area (Figure $6, B$ ). In the peri-infarct area, the protective effect was greatest in the CDC with VP64 treated 

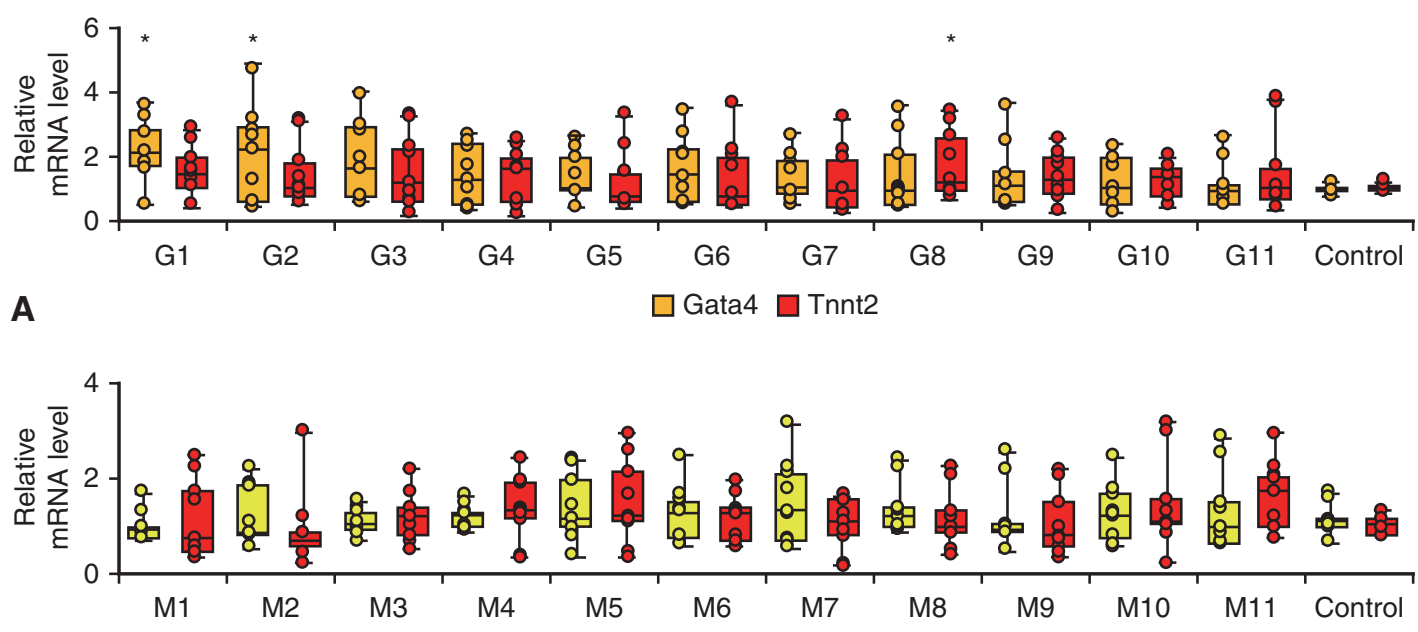

B

$\square$ Mef2c $\square$ Tnnt2
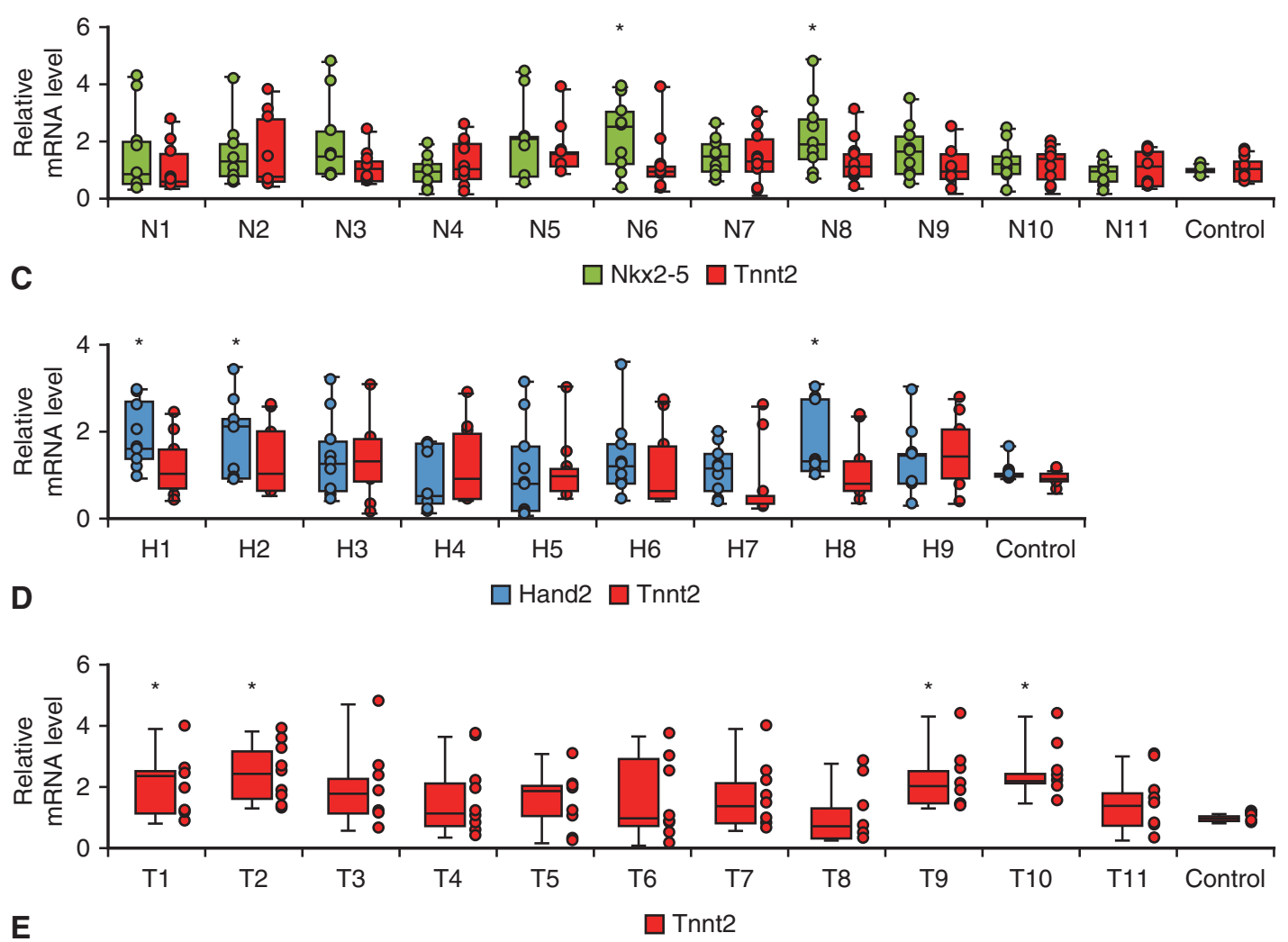

FIGURE 3. RNA-guided activation of endogenous rat genes. messenger RNA ( $m R N A$ ) expressions of each gene in cardiosphere-derived cells was determined by quantitative polymerase chain reaction (qPCR). A, Relative expression of Gata4 and Tnnt2 mRNA was coexpressed with orange and red lines, respectively. Two targets to the Gata4 gene (G1, G2) provided significant increases in Gata4 transcriptional levels but no significant difference in Tnnt2 transcriptional levels. One target to the Gata4 gene (G8) provided a significant increase in Tnnt 2 transcriptional levels but no significant difference in Gata4 transcriptional levels. B, Relative expression of Mef2c and Tnnt 2 mRNAs was coexpressed with yellow and red lines, respectively. None of the 11 single guide RNAs induced significant increases in either Mef2c or Tnnt2 transcriptional levels. C, Relative expression of Nkx2-5 and Tnnt2 mRNAs was coexpressed with green and red lines, respectively. Two targets to the $N k x 2-5$ gene (N6, N8) provided significant increases in $N k x 2-5$ transcriptional levels but no significant difference in Tnnt 2 transcriptional levels. D, Relative expression of Hand 2 and Tnnt 2 mRNAs was coexpressed with blue and red lines, respectively. Three targets to the Hand 2 gene (H1, H2 and H8) provided significant increases in Hand2 transcriptional levels but no significant difference in Tnnt 2 transcriptional levels. E, Relative expression of Tnnt 2 mRNA was expressed with red lines. Four targets of Tnnt2 gene (T1, T2, T9 and T10) provided significant increases in Tnnt2 transcriptional levels. The expression level was normalized via Gapdh and expressed in an arbitrary unit (AU). The upper and lower borders of the box represent the upper and lower quartiles. The middle horizontal line represents the median. The upper and lower whiskers represent the maximum and minimum values of nonoutliers. Extra dots represent outliers. Sample was $\mathrm{n}=9$ for each group. *Significant change compared with the control group at $P<.05$. 


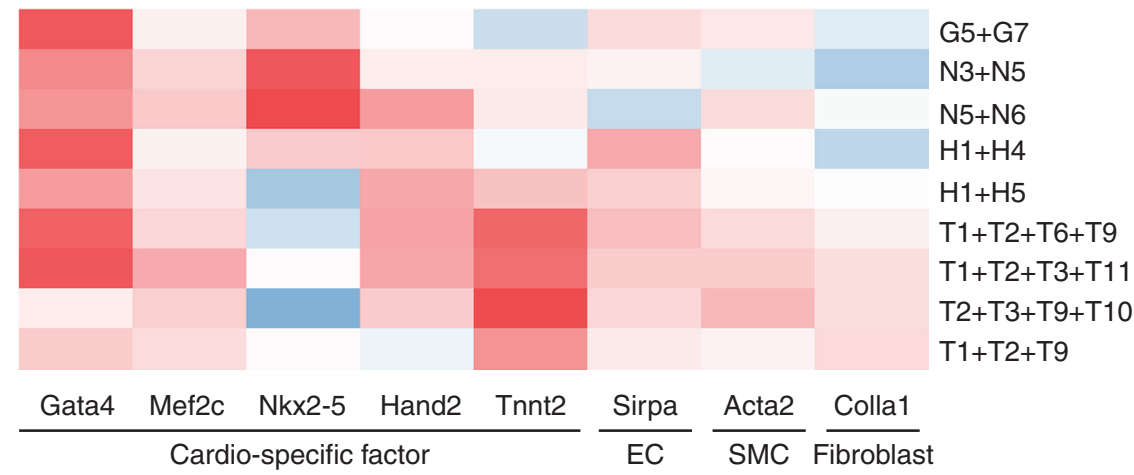

A
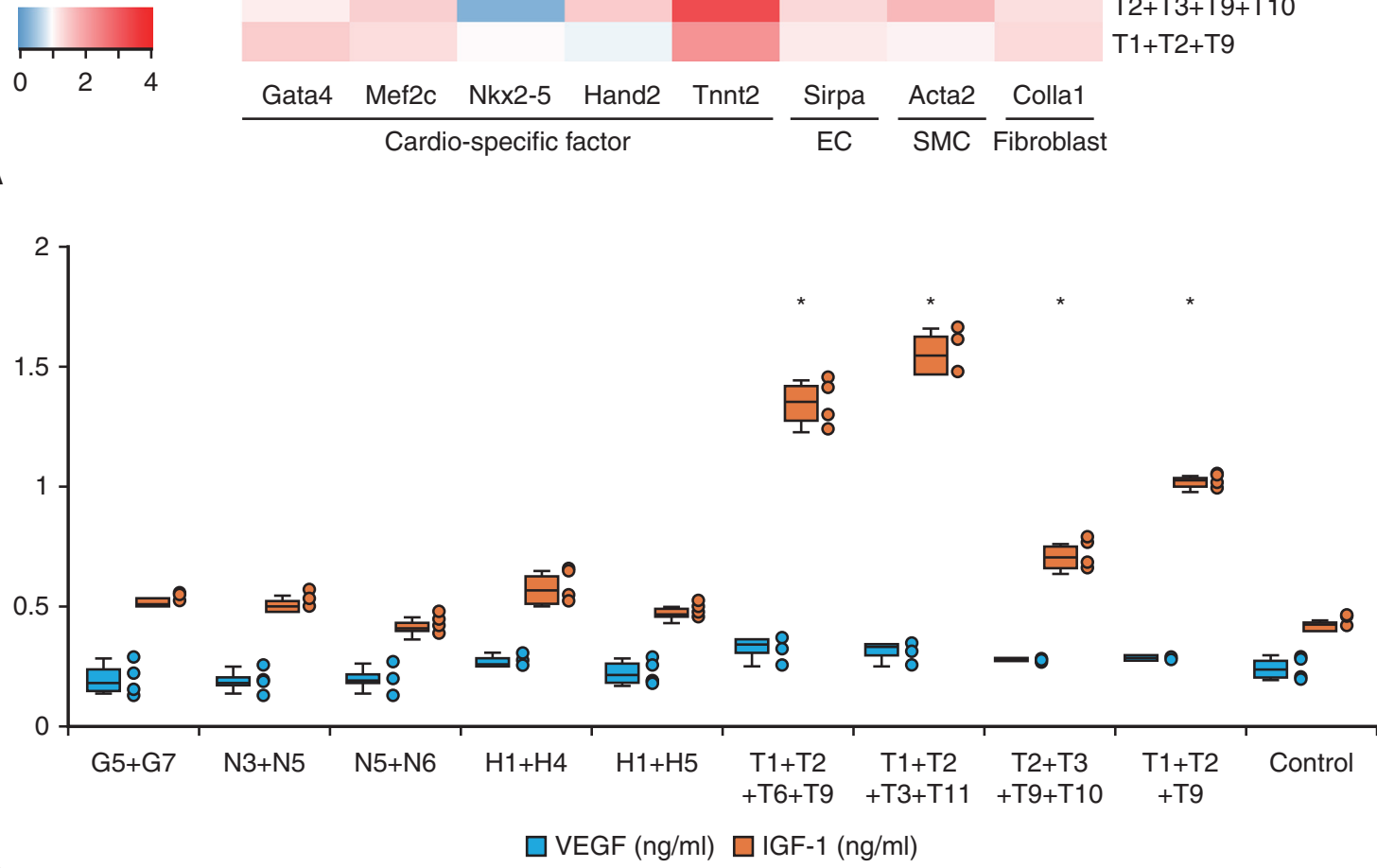

FIGURE 4. Screening of the synergistic activation of endogenous rat genes by RNA-guided activators. A, Gene expression levels of different cardiac cell types identified with the indicated combinations of single-guide RNA (sgRNAs). Several guides were designed and scored based on their combinatorial effects on activation of the differentiation factors that lead to the production of cardiomyocytes and other cardiac cell types. Messenger RNA (mRNA) expression in cardiosphere-derived cells of each guide combinations was determined by quantitative polymerase chain reaction (qPCR). Cardio-specific factors were enriched via coexpression of dCas9-VP64 with two or four combinations of sgRNAs. B, Measurement by enzyme-linked immunosorbent assay (ELISA) of the cumulative vascular endothelial growth factor $(V E G F)$ and insulin like growth factor 1 (IGF-1) concentrations secreted from cardiospherederived cells (CDCs) with each combination of sgRNAs. Coexpression of dCas9-VP64 with 4 sgRNAs (T1 + T2 + T3 + T9) as well as with subsets of 4 sgRNAs $(\mathrm{T} 1+\mathrm{T} 2+\mathrm{T} 3+\mathrm{T} 11)$ induced 3-fold synergistic activation of IGF-1 protein expression. The expression level was normalized via glyceraldehyde 3-phosphate dehydrogenase (Gapdh) and expressed in an arbitrary unit (AU). The upper and lower borders of the box represent the upper and lower quartiles. The middle horizontal line represents the median. The upper and lower whiskers represent the maximum and minimum values of nonoutliers. Extra dots represent outliers. Sample of $\mathrm{n}=4$ for each group. *Significant change compared with the control group at $P<.05$. EC, Endothelial cells; SMC, smooth muscle cells.

hearts, which had a smaller scar area than CDC treated hearts (Figure 6, $C$ and $D$ ).

\section{DISCUSSION}

A score of studies utilizing lineage-tracing has demonstrated that CDCs themselves and surrounding cells failed to differentiate into cardiomyocytes in vivo and that cell therapy did not improve cardiac function in adult murine infarct models although neonatal murine cardiomyocytes are actively cycling. ${ }^{17}$ In addition, other authors have questioned the differentiation potential of CDCs in vitro. Results from the Ardiosphere-Derived Autologous Stem Cells to Reverse Ventricular Dysfunction (CADUCEUS) trial, after a 1-year follow-up, described a subtle enhancement in the viability of cardiac muscle without benefit to cardiac function. ${ }^{8}$ In contrast with a meta-analysis of several cardiac clinical trials that showed that cell therapy provided no benefit in terms of left ventricular function after myocardial infarction, ${ }^{18}$ cell therapy trials using autologous CDCs for congenital heart disease enhanced ventricular function by reverse remodeling, improving heart failure status, ${ }^{19,20}$ and reducing late complications. ${ }^{21}$ These experimental 


\section{Echocardiography}

\section{$\square$ Control $\square$ CDC $\square$ CDC with VP46}

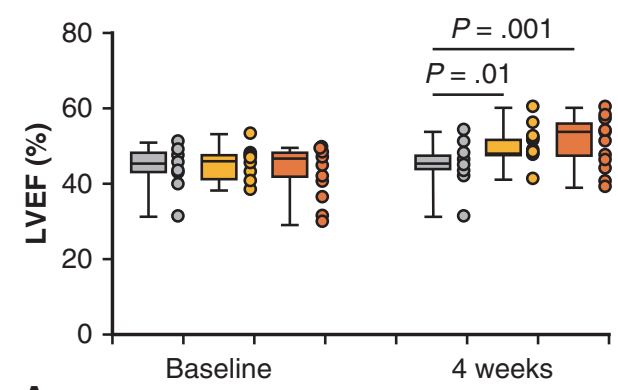

A

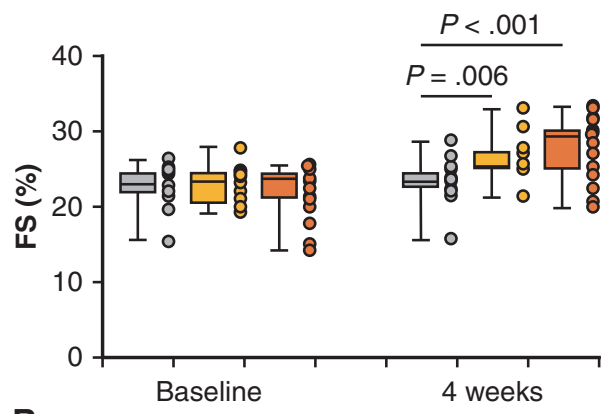

B
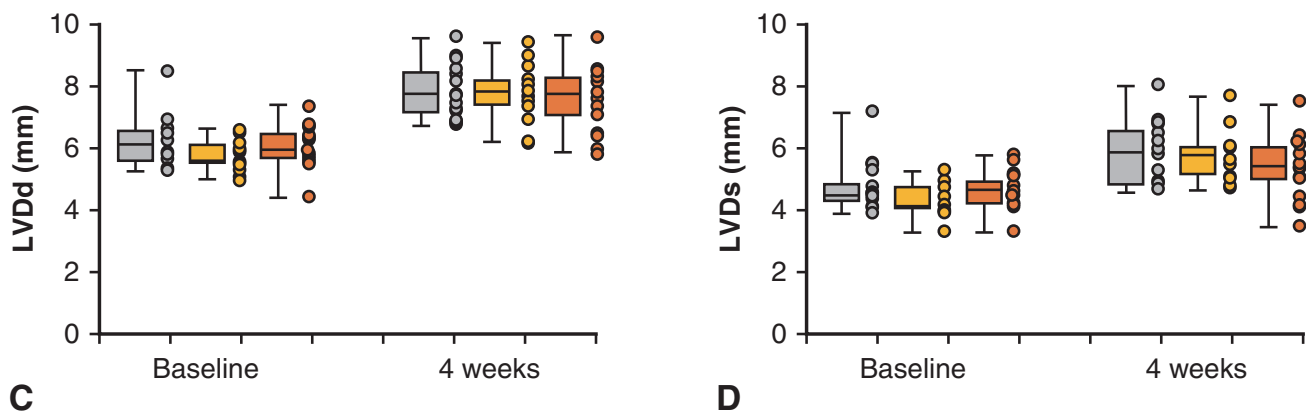

Hemodynamics
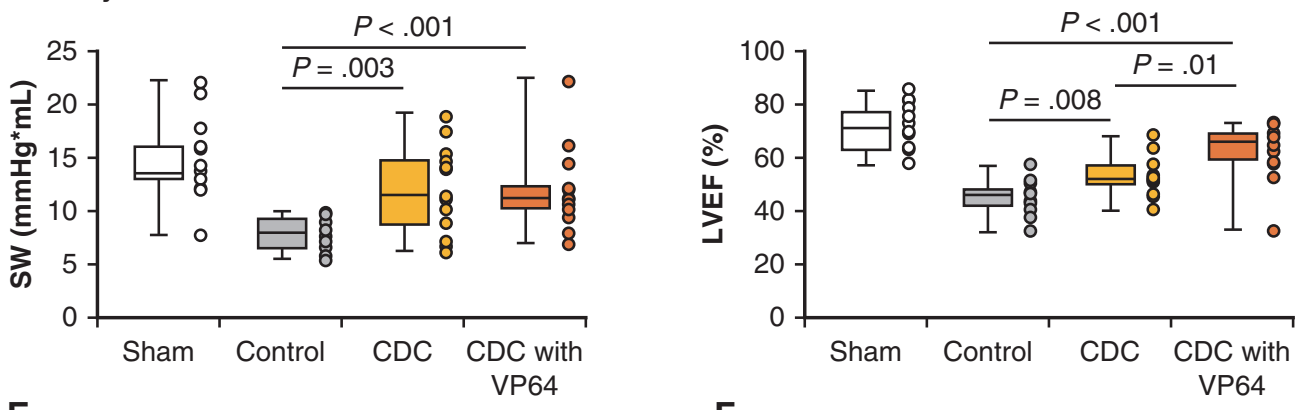

E

F
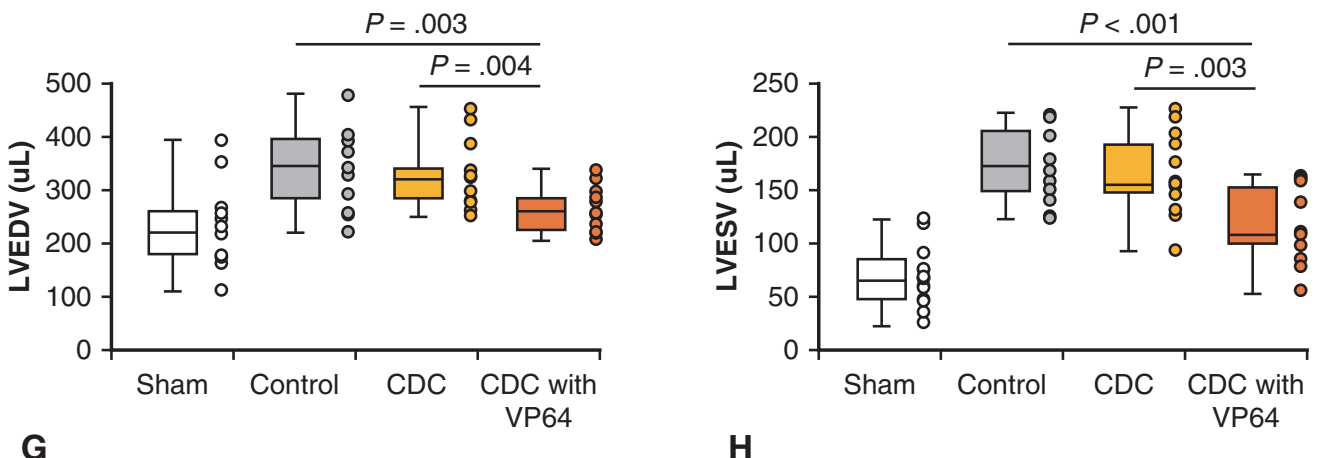

FIGURE 5. Functional and hemodynamic analysis of rat hearts. Echocardiography and cardiac catheterization were used for measurements in the control, cardiosphere-derived cell $(C D C)$, and CDC with VP64 groups. Echocardiography (A-D) was performed 1 day after left anterior descending (LAD) coronary artery ligation (Baseline) and 4 weeks after LAD ligation. After 4 weeks left ventricular ejection fraction (LVEF) and fractional shortening $(F S)$ were higher in rats in the CDC or CDC with VP64 group, compared with the control group. Cardiac catheterization (E-H) was performed 4 weeks after LAD ligation. Therapeutic effects were most pronounced in the CDC with VP64 group, which showed a significant improvement in LVEF, and a marked reduction in left ventricular end-diastolic volume (LVEDV) and left ventricular end-systolic volume (LVESV), compared with both control and CDC group. The upper and lower borders of the box represent the upper and lower quartiles. The middle horizontal line represents the median. The upper and lower whiskers represent the maximum and minimum values of nonoutliers. Extra dots represent outliers. Sample was $\mathrm{n}=14$ to 16 for each group. LVDd, Left ventricular enddiastolic dimension; $L V D s$, left ventricular end-systolic dimension; $S W$, stroke work. 


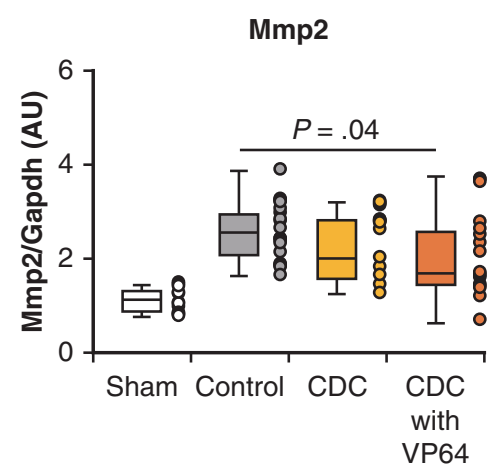

Timp2

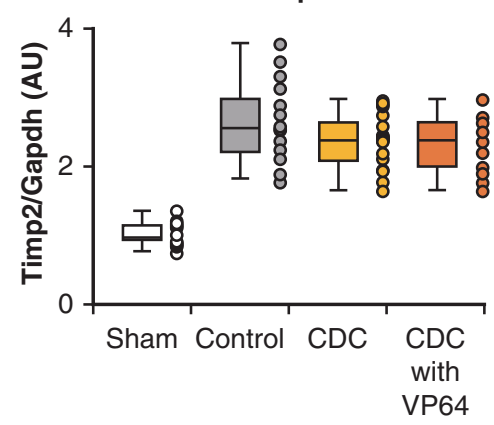

Col3a1
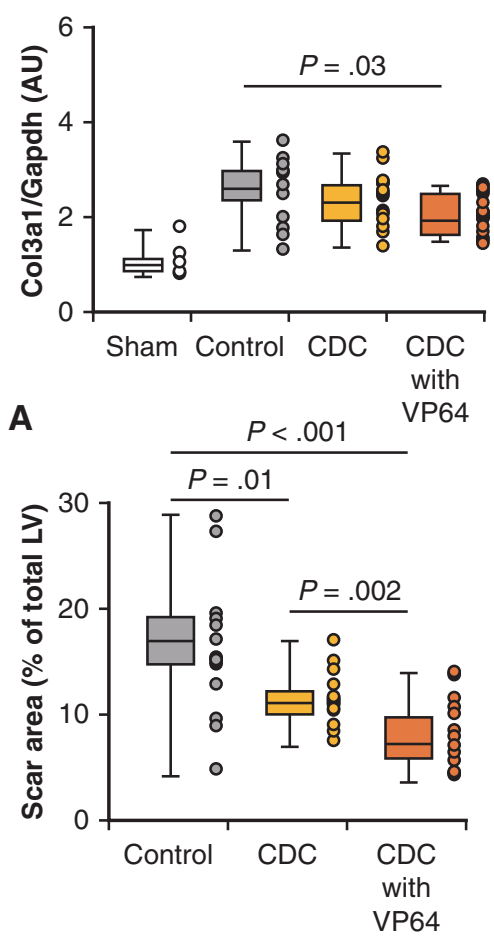

B

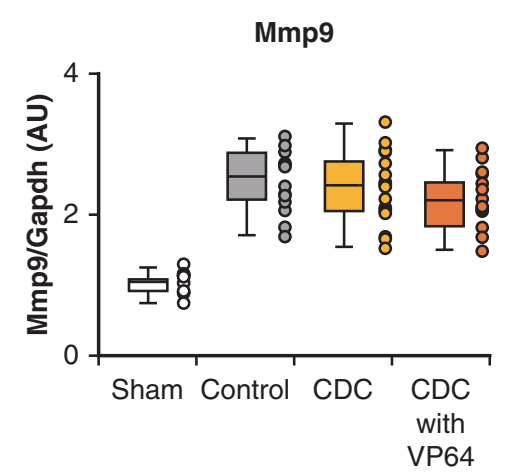

IL-6

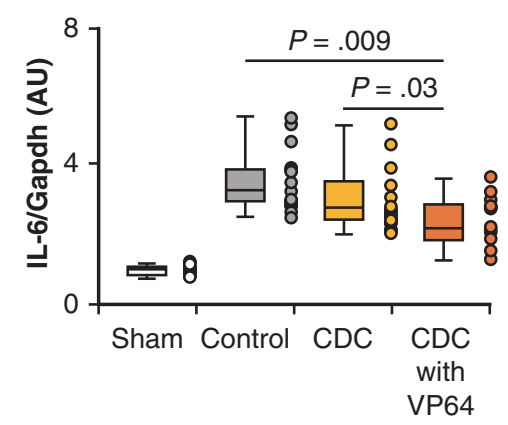

VEGFa
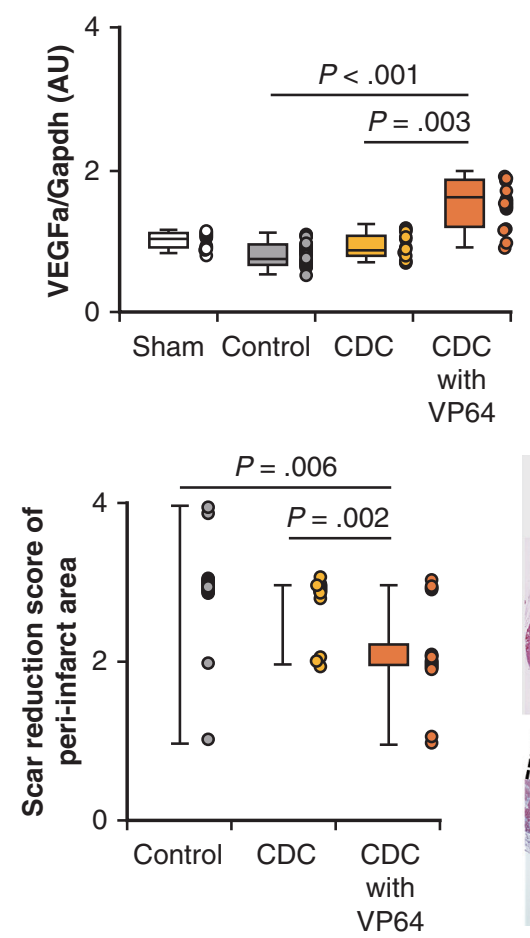

C

D
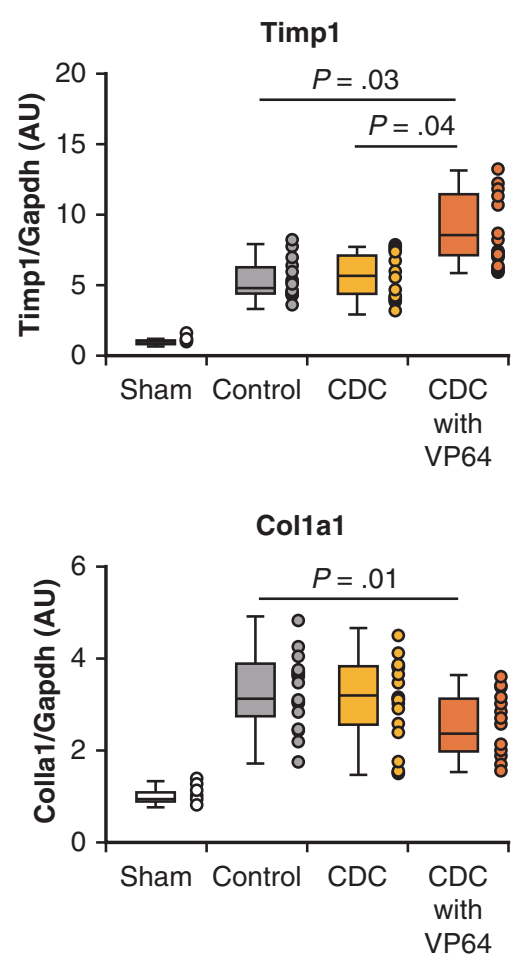

IGF-1
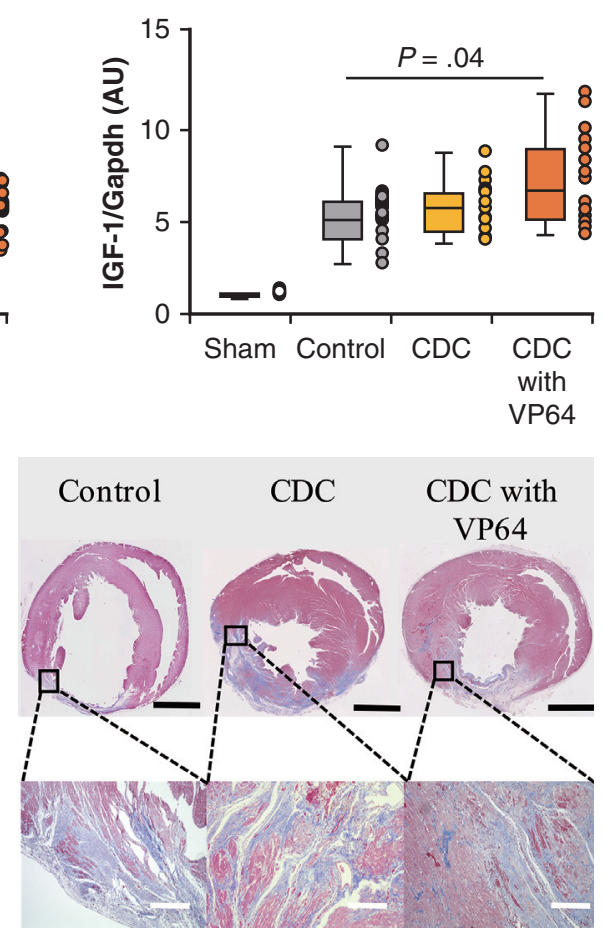

FIGURE 6. Gene expression analyses and ventricular remodeling in rats after cardiosphere-derived cell ( $C D C$ ) infusion. A, The left ventricular tissues obtained from sham operated rats and animals subjected to left anterior descending coronary artery (LAD) ligation were assessed by gene expression analyses. The levels of transcripts were compared between controls and CDC-injected animals. All results were normalized to Gapdh and expressed in an arbitrary unit $(A U)$. B, Scar area analysis by Masson's trichrome staining. C, Semiquantitative analysis of the scar reduction. The border zone of the myocardial infarction was graded on a subjective scale of 0 to 4 , corresponding to mild, moderate, marked, or severe fibrosis, respectively. D, Representative 
studies have suggested that the decline of cardiomyocyte replication might be associated with the absolute loss of intrinsic progenitor cells or reduced potential of preexisting mature myocyte proliferation during heart development. Therefore, the present study focused exclusively on the set back of differentiation potential of CDCs and intended to enhance the cardiomyogenic efficiency of CDCs to develop into a large population of cardiomyocytes by intrinsic transcriptional activation of cardio-specific differentiation factors (Gata4, Mef2c, Nkx2-5, Hand2, and Tnnt2) in the cellular environment itself via the CRISPR/ dCas9 gene transcriptional activation system.

A recent study used the CRISPR/dCas9 system to activate endogenous cardiac transcription factors such as Gata4, Mef2c, Tbx5, and Hand2 in differentiation of fibroblast into cardiomyocytes. A combination of miRNAs and the CRISPR/dCas9 system had an effect on the expression of endogenous cardiac transcription factors; however, the CRISPR/dCas9 system had no effect on reprogramming. Transcriptional activation systems such as CRISPR/dCas9 were ineffective in terms of the reprogramming, although it has not been reported in terms of inducing stem cell differentiation. To our knowledge, the present study was the first to use transcriptionally activated rat CDCs for therapy in a myocardial infarction model.

The CRISPR/dCas9 system successfully targeted DNA in bacterial and human cells, and dCas9 chimeras fused to transcriptional domains mediated targeted transcriptional regulation. ${ }^{22}$ In mammalian cells, it has also been demonstrated that dCas9-VPR can increase the expression of multiple genes in cells. In fact, the ability to enhance the transcription activity of the target gene using dCas9-VPR is more than 1000 times stronger than dCas9-VP64. It is an effective means to enhance the expression of specific proteins, but it is important to direct the cell differentiation closer to the natural environment when performing myocardial stem cell transplantation, which is expected to improve the environment inside and outside the transplanted cells. Therefore, a mild transcription enhancement system was selected to induce myocardial stem cells to differentiate into cardiomyocytes. Our experiments defined an RNAguided activator platform to induce the expression of endogenous genes in rat cells. sgRNAs targeting sites on either DNA strand and at the positions upstream, downstream, or at the transcription start site showed transcriptional activation at the Tnnt2 gene. Particularly, combining sets of 4 sgRNAs $(\mathrm{T} 1+\mathrm{T} 2+\mathrm{T} 6+\mathrm{T} 9)$ had successful activation of gene expression of cardio-specific factors (Figure 4, $A$ ). It is well known that DNA methylation has a relationship with transcriptional activity. Baumann and colleagues ${ }^{23}$ indicated that the removal of DNA methylation on the $\mathrm{CpG}$ islands has the highest potential to increase the proportion of cells activating transcription factors. In this study, we checked for the presence of $\mathrm{CpG}$ islands in each target region of the gene, but it was not wholly related to transcriptional activation.

The in vivo study revealed that transcriptionally activated CDCs improved cardiac function when injected into the peri-infarction zone by increasing ejection fraction and ventricular stroke work compared with PBS or nontranscriptionally activated CDCs. It has been shown that the grafted stem cells have the potential to secrete cytokines and growth factors through paracrine effects, protecting the remaining cells at the lesion site. However, it is also known that the grafted cells do not survive for long in the site. We measured CDC retention in the rat heart following sacrifice at day 28 after myocardial infarction; however, no retention was identified by tissue staining. Previous studies demonstrated that IGF-1 activated pathways that regulate several important physiological functions, including cell growth, proliferation and survival, ${ }^{24,25}$ and are expressed by cardiomyocytes. ${ }^{26}$ The secretion levels of IGF-1 were increased in transcriptional activated CDCs (Figure 4, B). This result suggests that preceded the proliferation of cardiomyocytes during cardiac regeneration and the occurrence of myocardial regeneration requires IGF-1.

We have identified endogenous regulatory regions responsible for an intrinsic activation of cardio-specific differentiation factors assisted via a CRISPR/dCas9 gene transcriptional system. This system could be combined with the external induction of conventional methods such as pretreatment strategies to improve therapeutic outcomes for patients with ischemic heart disease. In the future, by demonstrating the effectiveness of transiently inducing transcriptional activity, it is expected that not only an efficient use of existing CDC transplantation technology but also an expansion of indications for patients with congenital heart disease will be realized.

\section{CONCLUSIONS}

Intrinsic transcriptional activation of cardio-specific differentiation factors in the cellular environment by the CRISPR/dCas9 gene transcriptional system has the

images of typical Masson's trichrome staining of cardiac tissues in each group. Compared with the control and CDC groups, the injection of CDC with VP64 group significantly suppressed cardiac remodeling (matrix metalloproteinase type 2/9 [Mmp2], tissue inhibitor of metalloproteinase $1 / 2$ [Timp1], interleukin$6[I L-6]$, collagen type 1 [Collal], and collagen type 3 [Col3al]), increased cardiac growth factors (vascular endothelial growth factor A [VEGFa] and insulin-like growth factor $1[I G F-1]$ ), and reduced the scar area. Black scale bars: $5 \mathrm{~mm}$. White scale bar: $50 \mu \mathrm{m}$. The upper and lower borders of the box represent the upper and lower quartiles. The middle horizontal line represents the median. The upper and lower whiskers represent the maximum and minimum values of nonoutliers. Extra dots represent outliers. Sample was n $=14$ to 16 for each group. 
potential to overcome the setbacks of external induction of previously conducted cardiac regeneration efforts by producing a large population of cardiomyocytes that will, in turn, address the futuristic treatment of myocardial infarction.

\section{Conflict of Interest Statement}

The authors reported no conflicts of interest.

The Journal policy requires editors and reviewers to disclose conflicts of interest and to decline handling or reviewing manuscripts for which they may have a conflict of interest. The editors and reviewers of this article have no conflicts of interest.

\section{References}

1. Ashur C, Frishman WH. Cardiosphere-derived cells and ischemic heart failure Cardiol Rev. 2018;26:8-21.

2. Kolanowski TJ, Antos CL, Guan K. Making human cardiomyocytes up to date: derivation, maturation state and perspectives. Int J Cardiol. 2017;241:379-86.

3. Passier R, van Laake LW, Mummery CL. Stem-cell-based therapy and lessons from the heart. Nature. 2008;453:322-9.

4. Segers VF, Lee RT. Stem-cell therapy for cardiac disease. Nature. 2008;451: 937-42.

5. Houtgraaf JH, den Dekker WK, van Dalen BM, Springeling T, de Jong R, van Geuns RJ, et al. First experience in humans using adipose tissue-derived regenerative cells in the treatment of patients with ST-segment elevation myocardial infarction. J Am Coll Cardiol. 2012;59:539-40.

6. Hare JM, DiFede DL, Rieger AC, Florea V, Landin AM, El-Khorazaty J, et al. Randomized comparison of allogeneic versus autologous mesenchymal stem cells for nonischemic dilated cardiomyopathy: POSEIDON-DCM trial. J Am Coll Cardiol. 2017;69:526-37.

7. Bartunek J, Behfar A, Dolatabadi D, Vanderheyden M, Ostojic M, Dens J, et al. Cardiopoietic stem cell therapy in heart failure: the C-CURE (Cardiopoietic stem Cell therapy in heart failURE) multicenter randomized trial with lineagespecified biologics. J Am Coll Cardiol. 2013;61:2329-38.

8. Makkar RR, Smith RR, Cheng K, Malliaras K, Thomson LE, Berman D, et al. Intracoronary cardiosphere-derived cells for heart regeneration after myocardial infarction (CADUCEUS): a prospective, randomised phase 1 trial. Lancet. 2012; 379:895-904.

9. Ibrahim AG, Cheng K, Marban E. Exosomes as critical agents of cardiac regeneration triggered by cell therapy. Stem Cell Rep. 2014;2:606-19.

10. Jackson KA, Majka SM, Wang H, Pocius J, Hartley CJ, Majesky MW, et al. Regeneration of ischemic cardiac muscle and vascular endothelium by adult stem cells. J Clin Invest. 2001;107:1395-402.

11. Smith RR, Barile L, Cho HC, Leppo MK, Hare JM, Messina E, et al. Regenerative potential of cardiosphere-derived cells expanded from percutaneous endomyocardial biopsy specimens. Circulation. 2007;115:896-908.
12. Cheng K, Malliaras K, Smith RR, Shen D, Sun B, Blusztajn A, et al. Human cardiosphere-derived cells from advanced heart failure patients exhibit augmented functional potency in myocardial repair. JACC Heart Fail. 2014;2: 49-61.

13. Davis DR, Zhang Y, Smith RR, Cheng K, Terrovitis J, Malliaras K, et al. Validation of the cardiosphere method to culture cardiac progenitor cells from myocardial tissue. PLoS One. 2009;4:e7195.

14. Hou Y, Huang C, Cai X, Zhao J, Guo W. Improvements in the establishment of a rat myocardial infarction model. J Intl Med Res. 2011;39:1284-92.

15. Maeder ML, Linder SJ, Cascio VM, Fu Y, Ho QH, Joung JK. CRISPR RNA guided activation of endogenous human genes. Nat Methods. 2013;10:977-9.

16. Chimenti I, Smith RR, Li TS, Gerstenblith G, Messina E, Giacomello A, et al. Relative roles of direct regeneration versus paracrine effects of human cardiosphere-derived cells transplanted into infarcted mice. Circ Res. 2010; 106:971-80.

17. Kretzschmar K, Post Y, Bannier-Helaouet M, Mattiotti A, Drost J, Basak O, et al. Profiling proliferative cells and their progeny in damaged murine hearts. Proc Natl Acad Sci U S A. 2018;115:E12245-54.

18. Gyongyosi M, Wojakowski W, Lemarchand P, Lunde K, Tendera M, Bartunek J, et al. Meta-Analysis of Cell-based CaRdiac stUdiEs (ACCRUE) in patients with acute myocardial infarction based on individual patient data. Circ Res. 2015;116: 1346-60.

19. Ishigami S, Ohtsuki S, Tarui S, Ousaka D, Eitoku T, Kondo M, et al. Intracoronary autologous cardiac progenitor cell transfer in patients with hypoplastic left heart syndrome: the TICAP prospective phase 1 controlled trial. Circ Res. 2015; 116:653-64.

20. Ishigami S, Ohtsuki S, Eitoku T, Ousaka D, Kondo M, Kurita Y, et al. Intracoronary cardiac progenitor cells in single ventricle physiology: the PERSEUS (cardiac progenitor cell infusion to treat univentricular heart disease) randomized phase 2 trial. Circ Res. 2017;120:1162-73.

21. Sano T, Ousaka D, Goto T, Ishigami S, Hirai K, Kasahara S, et al. Impact of cardiac progenitor cells on heart failure and survival in single ventricle congenital heart disease. Circ Res. 2018;122:994-1005.

22. Perez-Pinera P, Kocak DD, Vockley CM, Adler AF, Kabadi AM, Polstein LR, et al. RNA-guided gene activation by CRISPR-Cas9-based transcription factors. Nat Methods. 2013;10:973-6.

23. Baumann V, Wiesbeck M, Breunig CT, Braun JM, Koferle A, Ninkovic J, et al. Targeted removal of epigenetic barriers during transcriptional reprogramming. Nat Commun. 2019;10:2119.

24. Toker A, Cantley LC. Signalling through the lipid products of phosphoinositide3-OH kinase. Nature. 1997:387:673-6.

25. Bagno LL, Carvalho D, Mesquita F, Louzada RA, Andrade B, KasaiBrunswick TH, et al. Sustained IGF-1 secretion by adipose-derived stem cells improves infarcted heart function. Cell Transplant. 2016;25: 1609-22.

26. Ren J, Samson WK, Sowers JR. Insulin-like growth factor I as a cardiac hormone: physiological and pathophysiological implications in heart disease. J Mol Cell Cardiol. 1999;31:2049-61.

Key Words: CRISPR/dCas9, cardiospere-derived cells, myocardial repair 
TABLE E1. (Rattus norvegicus strain mixed chromosome 15, Rnor_6.0; NC_005114.4, 46469474- 46298313) Gata4 gene target sites and associated oligonucleotides used to construct single guide RNA expression plasmids

\begin{tabular}{|c|c|c|c|}
\hline gRNA & Target site & Top oligo & Bottom oligo \\
\hline G1 & $\begin{array}{l}\text { Rattus norvegicus strain mixed chromosome 15, } \\
\text { Rnor_6.0; 46468238-46468256 }\end{array}$ & CACCGGAACCTTCAATATTGCAGT & AAACACTGCAATATTGAAGGTTCC \\
\hline G2 & $\begin{array}{l}\text { Rattus norvegicus strain mixed chromosome 15, } \\
\text { Rnor_6.0; 46467994-46468012 }\end{array}$ & CACCGGGGAACGTATTGCCAGGTC & AAACGACCTGGCAATACGTTCCCC \\
\hline G3 & $\begin{array}{l}\text { Rattus norvegicus strain mixed chromosome 15, } \\
\text { Rnor_6.0; 46461365-46461383 }\end{array}$ & CACCGACAGTTGAGATTGATACTC & AAACGAGTATCAATCTCAACTGTC \\
\hline G4 & $\begin{array}{l}\text { Rattus norvegicus strain mixed chromosome 15, } \\
\text { Rnor_6.0; 37198688-37198706 }\end{array}$ & CACCGGGAACAGAGAAACGTATGA & AAACTCATACGTTTCTCTGTTCCC \\
\hline G5 & $\begin{array}{l}\text { Rattus norvegicus strain mixed chromosome 15, } \\
\text { Rnor_6.0; 46433881-46433862 }\end{array}$ & CACCGTTATTTTTACGCGGTAATA & AAACTATTACCGCGTAAAAATAAC \\
\hline G6 & $\begin{array}{l}\text { Rattus norvegicus strain mixed chromosome 15, } \\
\text { Rnor_6.0; } 46433902-46433884\end{array}$ & CACCGGAAGGCTGCGGTAATCGAT & AAACATCGATTACCGCAGCCTTCC \\
\hline G7 & $\begin{array}{l}\text { Rattus norvegicus strain mixed chromosome 15, } \\
\text { Rnor_6.0; 46433710-46433692 }\end{array}$ & CACCGTTTGGATGGGTTCTAACGT & AAACACGTTAGAACCCATCCAAAC \\
\hline G8 & $\begin{array}{l}\text { Rattus norvegicus strain mixed chromosome 15, } \\
\text { Rnor_6.0; 46420482-46420464 }\end{array}$ & CACCGTGCTTCTGCTGAGCGGGAG & AAACCTCCCGCTCAGCAGAAGCAC \\
\hline G9 & $\begin{array}{l}\text { Rattus norvegicus strain mixed chromosome 15, } \\
\text { Rnor_6.0; 46420651-46420669 }\end{array}$ & CACCGGGTCACTCTTCACCTATCC & AAACGGATAGGTGAAGAGTGACCC \\
\hline G10 & $\begin{array}{l}\text { Rattus norvegicus strain mixed chromosome 15, } \\
\text { Rnor_6.0; 46413142-46413124 }\end{array}$ & CACCGCCTTTCACCACGGGTGATC & AAACGATCACCCGTGGTGAAAGGC \\
\hline G11 & $\begin{array}{l}\text { Rattus norvegicus strain mixed chromosome 15, } \\
\text { Rnor_6.0; 46382763-46382744 }\end{array}$ & CACCGGAAGAGCTTGCACCACGGT & AAACACCGTGGTGCAAGCTCTTCC \\
\hline
\end{tabular}

TABLE E2. (Rattus norvegicus strain mixed chromosome 2, Rnor_6.0; NC_005101.4, 11623289-11658516) Mef2c gene target sites and associated oligonucleotides used to construct single guide RNA expression plasmids

\begin{tabular}{|c|c|c|c|}
\hline gRNA & Target site & Top oligo & Bottom oligo \\
\hline M1 & $\begin{array}{l}\text { Rattus norvegicus strain mixed chromosome 2, } \\
\text { Rnor_6.0; 11663318-11663336 }\end{array}$ & CACCGTCTGGGAGTACTCCAAATA & AAACTATTTGGAGTACTCCCAGAC \\
\hline M2 & $\begin{array}{l}\text { Rattus norvegicus strain mixed chromosome 2, } \\
\quad \text { Rnor_6.0; 11663714-11663732 }\end{array}$ & CACCGAGCAGCTGTTAGGTATGAA & AАACTTCATACCTAACAGCTGCTC \\
\hline M3 & $\begin{array}{l}\text { Rattus norvegicus strain mixed chromosome 2, } \\
\quad \text { Rnor_6.0; 11667126-11667144 }\end{array}$ & CACCGAGAAGGGCGAGTTGAACGT & AAACACGTTCAACTCGCCCTTCTC \\
\hline M4 & $\begin{array}{l}\text { Rattus norvegicus strain mixed chromosome } 2 \text {, } \\
\text { Rnor_6.0; 11678176-11678158 }\end{array}$ & CACCGGTTGACTCTCCTCTCGAGC & AAACGCTCGAGAGGAGAGTCAACC \\
\hline M5 & $\begin{array}{l}\text { Rattus norvegicus strain mixed chromosome 2, } \\
\text { Rnor_6.0; 11694025-11694007 }\end{array}$ & CACCGAGGACTTATTAGATGACGT & AAACACGTCATCTAATAAGTCCTC \\
\hline M6 & $\begin{array}{l}\text { Rattus norvegicus strain mixed chromosome 2, } \\
\text { Rnor_6.0; 11719338-11719356 }\end{array}$ & CACCGTGAGCCGTCTCCAAATCGA & AAACTCGATTTGGAGACGGCTCAC \\
\hline M7 & $\begin{array}{l}\text { Rattus norvegicus strain mixed chromosome 2, } \\
\quad \text { Rnor_6.0; 11727017-11726999 }\end{array}$ & CACCGACTCTAGTGACCTGTTGGG & AAACCCCAACAGGTCACTAGAGTC \\
\hline M8 & $\begin{array}{l}\text { Rattus norvegicus strain mixed chromosome 2, } \\
\quad \text { Rnor_6.0; 11730921-11730902 }\end{array}$ & CACCGCGGTGGGCGCGTCTTCGAT & AAACATCGAAGACGCGCCCACCGC \\
\hline M9 & $\begin{array}{l}\text { Rattus norvegicus strain mixed chromosome 2, } \\
\quad \text { Rnor_6.0; 11731238-11731220 }\end{array}$ & CACCGCTCTCCTTGGGCGAGGAAC & AAACGTTCCTCGCCCAAGGAGAGC \\
\hline M10 & $\begin{array}{l}\text { Rattus norvegicus strain mixed chromosome 2, } \\
\quad \text { Rnor_6.0; 11742921-11742903 }\end{array}$ & CACCGCTGGATGATGCATCATGAG & AAACCTCATGATGCATCATCCAGC \\
\hline M11 & $\begin{array}{l}\text { Rattus norvegicus strain mixed chromosome 2, } \\
\text { Rnor_6.0; } 11752027-11752045\end{array}$ & CACCGGTACACGTTAGATTGCTTA & AAACTAAGCAATCTAACGTGTACC \\
\hline
\end{tabular}


TABLE E3. (Rattus norvegicus strain mixed chromosome 10, Rnor_6.0; NC_005109.4, 16633710-16640913) Nkx2-5 gene target sites and associated oligonucleotides used to construct single guide RNA expression plasmids

\begin{tabular}{|c|c|c|c|}
\hline gRNA & Target site & Top oligo & Bottom oligo \\
\hline N1 & $\begin{array}{l}\text { Rattus norvegicus strain mixed chromosome 10, } \\
\text { Rnor_6.0,; } 16633878-16633859\end{array}$ & CACCGGGGGCGGGTGGCGTATAAC & AAACGTTATACGCCACCCGCCCCC \\
\hline N2 & $\begin{array}{l}\text { Rattus norvegicus strain mixed chromosome 10, } \\
\text { Rnor_6.0,; } 16633867-16633848\end{array}$ & CACCGCGTATAACGGGGCCACATC & AAACGATGTGGCCCCGTTATACGC \\
\hline N3 & $\begin{array}{l}\text { Rattus norvegicus strain mixed chromosome 10, } \\
\text { Rnor_6.0,; 16634200-16634218 }\end{array}$ & CACCGGGCAGCAAACTGCTCAAGA & AAACTCTTGAGCAGTTTGCTGCCC \\
\hline N4 & $\begin{array}{l}\text { Rattus norvegicus strain mixed chromosome } 10 \text {, } \\
\quad \text { Rnor_6.0,; 16635778-16635760 }\end{array}$ & CACCGAAAGGGGCCGCGACACATT & AAACAATGTGTCGCGGCCCCTTTC \\
\hline N5 & $\begin{array}{l}\text { Rattus norvegicus strain mixed chromosome 10, } \\
\text { Rnor_6.0,; 16004425-16004406 }\end{array}$ & CACCGGCCTCGATGACAGGAGCGA & AAACTCGCTCCTGTCATCGAGGCC \\
\hline N6 & $\begin{array}{l}\text { Rattus norvegicus strain mixed chromosome 10, } \\
\quad \text { Rnor_6.0,; } 16004309-16004327\end{array}$ & CACCGGACTATTCCAAATGTGTCG & AAACCGACACATTTGGAATAGTCC \\
\hline N7 & $\begin{array}{l}\text { Rattus norvegicus strain mixed chromosome 10, } \\
\quad \text { Rnor_6.0,; 16640373-16640392 }\end{array}$ & CACCGAGGCTTGTGCGGCTCACGC & AAACGCGTGAGCCGCACAAGCCTC \\
\hline N8 & $\begin{array}{l}\text { Rattus norvegicus strain mixed chromosome 10, } \\
\quad \text { Rnor_6.0,; } 16009050-16009032\end{array}$ & CACCGTTAATCTTAGTAGGATCGA & AAACTCGATCCTACTAAGATTAAC \\
\hline N9 & $\begin{array}{l}\text { Rattus norvegicus strain mixed chromosome 10, } \\
\text { Rnor_6.0,; } 16008999-16008981\end{array}$ & CACCGTGTGAATTAGACCGTGTGT & AAACACACACGGTCTAATTCACAC \\
\hline N10 & $\begin{array}{l}\text { Rattus norvegicus strain mixed chromosome 10, } \\
\quad \text { Rnor_6.0,; } 16640703-16640685\end{array}$ & CACCGAAACAAAAGTGTCGGTCTT & AAACAAGACCGACACTTTTGTTTC \\
\hline N11 & $\begin{array}{l}\text { Rattus norvegicus strain mixed chromosome 10, } \\
\text { Rnor_6.0,; 16640748-16640766 }\end{array}$ & CACCGTGTTCTCGATCAATAAACC & AAACGGTTTATTGATCGAGAACAC \\
\hline
\end{tabular}

TABLE E4. (Rattus norvegicus strain mixed chromosome 16, Rnor_6.0; NC_005115.4, 36375199-36369838) Hand2 gene target sites and associated oligonucleotides used to construct single guide RNA expression plasmids

\begin{tabular}{|c|c|c|c|}
\hline gRNA & Target site & Top oligo & Bottom oligo \\
\hline H1 & $\begin{array}{l}\text { Rattus norvegicus strain mixed chromosome 16, } \\
\text { Rnor_6.0; 36374968-36374987 }\end{array}$ & CACCGGCGGTATGGAATCCCATAA & AAACTTATGGGATTCCATACCGCC \\
\hline $\mathrm{H} 2$ & $\begin{array}{l}\text { Rattus norvegicus strain mixed chromosome 16, } \\
\text { Rnor_6.0; } 36374554-36374535\end{array}$ & CACCGTTTTATTGCGGAGAGCGCG & AAACCGCGCTCTCCGCAATAAAAC \\
\hline H3 & $\begin{array}{l}\text { Rattus norvegicus strain mixed chromosome 16, } \\
\text { Rnor_6.0; 36374493-36374512 }\end{array}$ & CACCGAGGCTCCTCACGCCAATCC & AAACGGATTGGCGTGAGGAGCCTC \\
\hline $\mathrm{H} 4$ & $\begin{array}{l}\text { Rattus norvegicus strain mixed chromosome 16, } \\
\text { Rnor_6.0; } 36374489-36374471\end{array}$ & CACCGCGACATATATTAACCCGAG & AAACCTCGGGTTAATATATGTCGC \\
\hline H5 & $\begin{array}{l}\text { Rattus norvegicus strain mixed chromosome 16, } \\
\text { Rnor_6.0; 36374115-36374097 }\end{array}$ & CACCGCAAGAACCCACGAGCTGGT & AAACACCAGCTCGTGGGTTCTTGC \\
\hline H6 & $\begin{array}{l}\text { Rattus norvegicus strain mixed chromosome 16, } \\
\text { Rnor_6.0; } 36374028-36374047\end{array}$ & CACCGGTGGGGTCGCTACTCAGCG & AAACCGCTGAGTAGCGACCCCACC \\
\hline $\mathrm{H} 7$ & $\begin{array}{l}\text { Rattus norvegicus strain mixed chromosome 16, } \\
\quad \text { Rnor_6.0; } 36373782-36373800\end{array}$ & CACCGCCCGGCACCGGTGCGCCCT & AAACAGGGCGCACCGGTGCCGGGC \\
\hline $\mathrm{H} 8$ & $\begin{array}{l}\text { Rattus norvegicus strain mixed chromosome 16, } \\
\text { Rnor_6.0; 36373698-36373679 }\end{array}$ & CACCGGCCCCCCTCTGCGGCTGCA & AAACTGCAGCCGCAGAGGGGGGCC \\
\hline H9 & $\begin{array}{l}\text { Rattus norvegicus strain mixed chromosome 16, } \\
\text { Rnor_6.0; 36373608-36373627 }\end{array}$ & CACCGGGCTCCGGCCTCGGGCGAT & AAACATCGCCCGAGGCCGGAGCCC \\
\hline
\end{tabular}


TABLE E5. (Rattus norvegicus strain mixed chromosome 13, Rnor_6.0; NC_005112.4, 52660347-52669436) Tnnt2 gene target sites and associated oligonucleotides used to construct single guide RNA expression plasmids

\begin{tabular}{|c|c|c|c|}
\hline gRNA & Target site & Top oligo & Bottom oligo \\
\hline $\mathrm{T} 1$ & $\begin{array}{l}\text { Rattus norvegicus strain mixed chromosome 13, } \\
\text { Rnor_6.0; 52661504-52661522 }\end{array}$ & CACCGCCAACTCATAGATTCCCGG & AAACCCGGGAATCTATGAGTTGGC \\
\hline $\mathrm{T} 2$ & $\begin{array}{l}\text { Rattus norvegicus strain mixed chromosome 13, } \\
\text { Rnor_6.0; } 52661545-52661564\end{array}$ & CACCGTAAAAAATGGGGCTTCCAT & AAACATGGAAGCCCCATTTTTTAC \\
\hline $\mathrm{T} 3$ & $\begin{array}{l}\text { Rattus norvegicus strain mixed chromosome 13, } \\
\text { Rnor_6.0; 52661707-52661689 }\end{array}$ & CACCGAGGGGAGGGGCAGCATCCC & AAACGGGATGCTGCCCCTCCCCTC \\
\hline $\mathrm{T} 4$ & $\begin{array}{l}\text { Rattus norvegicus strain mixed chromosome 13, } \\
\text { Rnor_6.0; 52662895-52662877 }\end{array}$ & CACCGTTTGACAGGTGCCCGGCAC & AAACGTGCCGGGCACCTGTCAAAC \\
\hline T5 & $\begin{array}{l}\text { Rattus norvegicus strain mixed chromosome 13, } \\
\text { Rnor_6.0; } 52662924-52662906\end{array}$ & CACCGAACACAATGGGGGGGGTGT & AAACACACCCСCСCCATTGTGTTC \\
\hline T6 & $\begin{array}{l}\text { Rattus norvegicus strain mixed chromosome 13, } \\
\text { Rnor_6.0; 52662946-52662964 }\end{array}$ & CACCGTGCACATTCCTCCCACCGT & AAACACGGTGGGAGGAATGTGCAC \\
\hline $\mathrm{T} 7$ & $\begin{array}{l}\text { Rattus norvegicus strain mixed chromosome 13, } \\
\text { Rnor_6.0; 52662854-52662836 }\end{array}$ & CACCGCACGCCATATAAGCTCATG & AAACCATGAGCTTATATGGCGTGC \\
\hline $\mathrm{T} 8$ & $\begin{array}{l}\text { Rattus norvegicus strain mixed chromosome 13, } \\
\text { Rnor_6.0; 52662807-52662825 }\end{array}$ & CACCGATAGCTTTATCTGAGCAGC & AAACGCTGCTCAGATAAAGCTATC \\
\hline T9 & $\begin{array}{l}\text { Rattus norvegicus strain mixed chromosome 13, } \\
\text { Rnor_6.0; } 52664922-52664904\end{array}$ & CACCGATGGTGTCTTAACAGGGGG & AAACCCСССТGTTAAGACACCATC \\
\hline $\mathrm{T} 10$ & $\begin{array}{l}\text { Rattus norvegicus strain mixed chromosome 13, } \\
\text { Rnor_6.0; 52666215-52666197 }\end{array}$ & CACCGGGCTCCGCCCACAGTTGCC & AAACGGCAACTGTGGGCGGAGCCC \\
\hline T11 & $\begin{array}{l}\text { Rattus norvegicus strain mixed chromosome 13, } \\
\text { Rnor_6.0; 52664944-52664962 }\end{array}$ & CACCGTACTATCTTAATATGGGGG & AAACCCCCCATATTAAGATAGTAC \\
\hline
\end{tabular}

TABLE E6. The primers used in this study. The primers used in the quantitative polymerase chain reaction analysis employed in this study are shown

\begin{tabular}{ll}
\hline Gene & Primer \\
\hline Gapdh & Rn01775763_g1 \\
Gata4 & Rn01530459_m1 \\
\hline Mef2c & Rn01494040_m1 \\
Nkx2-5 & Rn00586428_m1 \\
\hline Hand2 & Rn00575515_m1 \\
Tnnt2 & Rn00562059_m1 \\
\hline Sirpa & Rn00564609_m1 \\
\hline Acta2 & Rn01759928_g1 \\
\hline Colla1 & Rn01463848_m1 \\
Mmp2 & Rn01538170_m1 \\
\hline Mmp9 & Rn00579162_m1 \\
Timp1 & Rn00579162_g1 \\
Timp2 & Rn00573232_m1 \\
\hline IL6 & Rn01410330_m1 \\
\hline Col3a1 & Rn01437681_m1 \\
VEGFa & Rn01511602_m1 \\
\hline IGF-1 & Rn00710306_m1 \\
\hline
\end{tabular}


TABLE E7. Expression of the synergistic activation of endogenous rat genes by RNA-guided activators

\begin{tabular}{|c|c|c|c|c|c|c|c|c|}
\hline \multirow[b]{2}{*}{ Subset of RNA } & \multicolumn{8}{|c|}{ Differentiation factor } \\
\hline & Gata4 & Mef2c & Nkx2-5 & Hand2 & Tnnt2 & Sirpa & Acta2 & Colla1 \\
\hline $\mathrm{G} 5+\mathrm{G} 7$ & $3.1 \pm 0.4^{*}$ & $1.1 \pm 0.4$ & $1.7 \pm 0.6$ & $1.0 \pm 0.3$ & $0.8 \pm 0.2$ & $1.3 \pm 0.2$ & $1.2 \pm 0.4$ & $0.9 \pm 0.2$ \\
\hline $\mathrm{N} 3+\mathrm{N} 5$ & $2.3 \pm 0.6$ & $1.4 \pm 0.4$ & $3.1 \pm 0.5^{*}$ & $1.1 \pm 0.3$ & $1.2 \pm 0.4$ & $1.1 \pm 0.3$ & $0.9 \pm 0.3$ & $0.6 \pm 0.3$ \\
\hline $\mathrm{N} 5+\mathrm{N} 6$ & $2.1 \pm 0.5$ & $1.5 \pm 0.4$ & $3.3 \pm 0.4^{*}$ & $2.1 \pm 0.4^{*}$ & $1.2 \pm 0.5$ & $0.7 \pm 0.2$ & $1.3 \pm 0.4$ & $1.0 \pm 0.2$ \\
\hline $\mathrm{H} 1+\mathrm{H} 4$ & $3.0 \pm 0.7^{*}$ & $1.1 \pm 0.3$ & $1.5 \pm 0.6$ & $1.5 \pm 0.4$ & $1.0 \pm 0.2$ & $1.9 \pm 0.2^{*}$ & $1.0 \pm 0.2$ & $0.7 \pm 0.2$ \\
\hline $\mathrm{H} 1+\mathrm{H} 5$ & $2.1 \pm 0.7$ & $1.2 \pm 0.3$ & $0.6 \pm 0.1^{*}$ & $1.9 \pm 0.4$ & $1.6 \pm 0.3$ & $1.5 \pm 0.2$ & $1.0 \pm 0.3$ & $1.0 \pm 0.2$ \\
\hline $\mathrm{T} 1+\mathrm{T} 2+\mathrm{T} 3+\mathrm{T} 9$ & $2.9 \pm 0.5^{*}$ & $1.4 \pm 0.3$ & $0.8 \pm 0.2$ & $2.0 \pm 0.3^{*}$ & $2.8 \pm 0.5^{*}$ & $1.6 \pm 0.2$ & $1.3 \pm 0.4$ & $1.1 \pm 0.3$ \\
\hline $\mathrm{T} 1+\mathrm{T} 2+\mathrm{T} 3+\mathrm{T} 11$ & $3.1 \pm 0.6^{*}$ & $1.9 \pm 0.6$ & $1.0 \pm 0.1$ & $1.9 \pm 0.5$ & $2.7 \pm 0.7^{*}$ & $1.5 \pm 0.2$ & $1.5 \pm 0.3$ & $1.3 \pm 0.3$ \\
\hline $\mathrm{T} 2+\mathrm{T} 3+\mathrm{T} 9+\mathrm{T} 10$ & $1.1 \pm 0.1$ & $1.4 \pm 0.4$ & $0.3 \pm 0.1^{*}$ & $1.5 \pm 0.3$ & $3.2 \pm 0.5^{*}$ & $1.3 \pm 0.2$ & $1.7 \pm 0.3$ & $1.3 \pm 0.3$ \\
\hline $\mathrm{T} 1+\mathrm{T} 2+\mathrm{T} 9$ & $1.5 \pm 0.2$ & $1.3 \pm 0.2$ & $1.0 \pm 0.1$ & $0.9 \pm 0.1$ & $2.2 \pm 0.4^{*}$ & $1.2 \pm 0.2$ & $1.1 \pm 0.2$ & $1.3 \pm 0.3$ \\
\hline Control & $1.0 \pm 0.2$ & $1.0 \pm 0.2$ & $1.0 \pm 0.0$ & $1.0 \pm 0.1$ & $1.0 \pm 0.2$ & $1.0 \pm 0.2$ & $1.0 \pm 0.2$ & $1.0 \pm 0.2$ \\
\hline
\end{tabular}

Each data point represents the mean \pm standard error of the mean. The expression level was normalized via gapdh and expressed in an arbitrary unit. *Significant change compared with the control group.

TABLE E8. Cardiac function of experimental groups on echocardiographic parameters

\begin{tabular}{|c|c|c|c|c|c|}
\hline \multirow[b]{2}{*}{ Parameter } & \multirow[b]{2}{*}{ Time (d) } & \multicolumn{4}{|c|}{ Experimental group } \\
\hline & & Sham $(n=14)$ & Control $(n=16)$ & CDC $(\mathbf{n}=16)$ & CDC with VP64 $(n=16)$ \\
\hline \multirow[t]{2}{*}{$\operatorname{LVEF}(\%)$} & 1 & $68.31 \pm 3.96$ & $44.87 \pm 4.74^{*}$ & $45.02 \pm 4.25^{*}$ & $43.76 \pm 6.21^{*}$ \\
\hline & 28 & $68.87 \pm 3.49$ & $44.98 \pm 4.89^{*}$ & $49.77 \pm 4.51^{*}, \dagger$ & $52.21 \pm 6.50^{*}, \dagger$ \\
\hline \multirow[t]{2}{*}{$\% \mathrm{FS}(\%)$} & 1 & $38.94 \pm 3.45$ & $22.76 \pm 2.64^{*}$ & $22.73 \pm 2.51^{*}$ & $22.14 \pm 3.55^{*}$ \\
\hline & 28 & $39.60 \pm 2.80$ & $23.23 \pm 2.78^{*}$ & $26.28 \pm 2.82^{*}, \dagger$ & $27.87 \pm 4.10^{*}, \dagger$ \\
\hline \multirow[t]{2}{*}{ LVDd (mm) } & 1 & $6.12 \pm 0.65$ & $6.22 \pm 0.83$ & $5.77 \pm 0.50$ & $6.07 \pm 0.66$ \\
\hline & 28 & $6.52 \pm 0.62$ & $7.85 \pm 0.89^{*}$ & $7.83 \pm 0.94 *$ & $7.64 \pm 1.00^{*}$ \\
\hline \multirow[t]{2}{*}{ LVDs (mm) } & 1 & $3.80 \pm 0.51$ & $4.67 \pm 0.81^{*}$ & $4.28 \pm 0.52 *$ & $4.61 \pm 0.60^{*}$ \\
\hline & 28 & $4.00 \pm 0.41$ & $5.80 \pm 0.99^{*}$ & $5.76 \pm 0.86^{*}$ & $5.34 \pm 0.98^{*}$ \\
\hline \multirow[t]{2}{*}{$\mathrm{SV}(\mu \mathrm{L})$} & 1 & $128.82 \pm 30.23$ & $84.71 \pm 20.77^{*}$ & $73.23 \pm 14.27 *$ & $80.70 \pm 22.77^{*}$ \\
\hline & 28 & $154.73 \pm 27.77$ & $140.62 \pm 26.73$ & $165.99 \pm 35.07 \dagger$ & $165.16 \pm 47.32$ \\
\hline
\end{tabular}

Values are presented as mean \pm standard deviation. Day 1 shows baseline values (after myocardial infarction and before myocardial injection) for 3 groups (Control, CDC, and CDC with VP64 group). $C D C$, Cardiosphere-derived cell; $F S$, fractional shortening; $L V D d$, left ventricular end-diastolic dimension; $L V D s$, left ventricular end-systolic dimension; $L V E F$, left ventricular ejection fraction; $S V$, stroke volume. *Significant change compared with the sham group. $\dagger$ Significant change compared with the control group at $P<.05$. 
TABLE E9. Cardiac function of experimental groups on left ventricle catheter study

\begin{tabular}{|c|c|c|c|c|}
\hline \multirow[b]{2}{*}{ Parameter } & \multicolumn{4}{|c|}{ Experimental group } \\
\hline & Sham $(n=14)$ & Control $(\mathbf{n}=16)$ & $\operatorname{CDC}(\mathbf{n}=16)$ & CDC with VP64 $(n=16)$ \\
\hline $\operatorname{LVEF}(\%)$ & $69.78 \pm 8.35$ & $44.12 \pm 6.43^{*}, \dagger$ & $52.46 \pm 7.72 *, \dagger$ & $61.95 \pm 10.58^{*}, \dagger$ \\
\hline LVEDV $(\mu \mathrm{L})$ & $251.56 \pm 107.64$ & $337.80 \pm 74.83^{*}$ & $324.22 \pm 62.53^{*}$ & $260.07 \pm 40.51 \dagger, \ddagger$ \\
\hline $\operatorname{LVESV}(\mu \mathrm{L})$ & $70.10 \pm 32.03$ & $171.98 \pm 35.48^{*}$ & $162.55 \pm 38.33^{*}$ & $115.62 \pm 34.62^{*}, \dagger, \ddagger$ \\
\hline $\mathrm{CO}(\mathrm{mL} / \mathrm{min})$ & $47.88 \pm 12.16$ & $36.88 \pm 9.09^{*}$ & $44.86 \pm 8.16 \dagger$ & $45.56 \pm 11.73 \dagger$ \\
\hline $\mathrm{SV}(\mu \mathrm{L})$ & $156.01 \pm 42.96$ & $131.72 \pm 27.71$ & $172.19 \pm 33.39 \dagger$ & $174.41 \pm 37.73 \dagger$ \\
\hline $\mathrm{SW}(\mathrm{mm} \mathrm{Hg} \times \mathrm{mL})$ & $14.71 \pm 3.74$ & $7.84 \pm 1.59 *$ & $12.10 \pm 4.16 \dagger$ & $12.03 \pm 3.80^{\dagger}$ \\
\hline
\end{tabular}

